\title{
ESTIMATION OF THE AIR PERMEABILITY COEFFICIENT AND THE RADIUS OF VACUUM INFLUENCE FOR CONTAMINATED SOIL AND GROUNDWATER REMEDIATION
}

\author{
Yoshiniko Hibi ${ }^{\text {i) }}$, Kenji Jinno ${ }^{\text {ii) }}$, Kentaro Masuoka ${ }^{\text {iii) }}$ and Junichi Kawabata ${ }^{\text {iv) }}$
}

\begin{abstract}
The air permeability coefficient and the radius of vacuum influence are important parameters in the design of soil vapor extraction systems for removing volatile organic chemicals, but procedures for obtaining these parameters have not yet been established. We developed procedures using previously derived analytical equations for the relationship between air discharge rates from an extraction well and the air pressure head generated in the neighborhood of the extraction well in soil with a uniform degree of water saturation in order to obtain these parameters in soil with varying degrees of water saturation. We verified that these procedures could be used to obtain these parameters by using air permeability test data from five sites. In addition, we demonstrated that these procedures could also be applied to gravel soil with fast air flow.
\end{abstract}

Key words: air permeability coefficient, air permeability test, contaminated soil, gas phase of soil, numerical simulation, radius of vacuum influence (IGC: C8/C9/E7)

\section{INTRODUCTION}

Unsaturated soils in some areas are contaminated with volatile organic chemicals (VOCs), such as trichloroethylene, tetrachloroethylene, tetrachloromethane, dichloroethane, and trichloroethane, because of leaks from storage tanks or pipelines or illegal disposal. These VOCs are removed from soil by using a soil vapor extraction (SVE) technique involving extraction wells installed in unsaturated soil (Helmig, 1997; Gerke et al., 1999).

The air permeability coefficient and the radius of vacuum influence are important parameters in the design of SVE systems. The locations of the extraction wells and the air extraction rate from each extraction well are determined by using these two parameters. However, SVE systems are often designed empirically without rigorous analyses and by assuming a uniform degree of water saturation in the soil (McWhorter, 1990; Baehr and Hult, 1991; Shan et al., 1992; US Army Corps of Engineers, 2002) because the analytical equations for the air permeability coefficient in soil with variable degree of water saturation are complex (US Army Corps of Engineers, 2002).

The analytical equations for the air permeability coefficient in soil with the uniform degree of water saturation, such as a layer of sand or gravel some distance above the groundwater table, are simpler than those for soil with variable degree of water saturation, such as the layer of silt or sand directly above the groundwater table. These simpler analytical equations have the advantage of calculation efficiency of the air permeability coefficient, and they are convenient for use during air permeability tests on site. However, procedures for obtaining the air permeability coefficient and the radius of vacuum influence using analytical equations for the relationship between the distribution of the air pressure head and air discharge rates in soil with uniform degree of water saturation have not yet been established. Moreover, the relationship between the degree of air pressure head and air discharge rates obtained with the analytical equations for the air permeability coefficient in soil with uniform degree of water saturation have not been compared with those obtained by air permeability tests carried out in the field, and the limits of those equations have not been validated. To address these problems, we carried out simulations with finite-element method for air-water two-phase flow in soil and obtained the relationships between the distribution of the air pressure head and air discharge rates in soil with uniform or variable degree of water saturation. These relationships were then compared with those gained by the analytical equations for the air

i) Department of Environmental Science and Technology, Faculty of Science and Technology, Meijo University, Nagoya, Aichi, Japan (hibiy@ ccmfs.meijo-u.ac.jp).

ii) Department of Urban and Environment Engineering, Graduate School of Engineering, Kyushu University, Fukuoka, Japan.

iii) Geo-environment Engineering Section, Civil Engineering Research Institute, Technology Center, Taisei Corporation, Kanagawa, Japan.

iv) Geotechnical Engineering and Soil Environment Group, Kajima Technical Research Institute, Kajima Corporation, Tokyo, Japan.

The manuscript for this paper was received for review on February 10, 2009; approved on September 29, 2009.

Written discussions on this paper should be submitted before September 1, 2010 to the Japanese Geotechnical Society, 4-38-2, Sengoku, Bunkyo-ku, Tokyo 112-0011, Japan. Upon request the closing date may be extended one month. 
permeability coefficient in soil with uniform degree of water saturation. Consequently, this paper clarified the conditions under which the air pressure head obtained by the simulation was similar to that obtained by analytical equations. We then developed procedures for obtaining the air permeability coefficient and the radius of vacuum influence based on the above comparisons and the analytical equations. Finally, we applied these procedures to air permeability tests at five sites. The numerical simulation incorporated the compressibility of air and the variation of water saturation in unsaturated soil.

\section{PROCEDURES FOR OBTAINING THE AIR PERMEABILITY COEFFICIENT}

Many studies have applied Darcy's law for air flow to the air phase in soil (Abriola and Pinder, 1985; Thorstenson and Pollock, 1989; Baehr and Bruell, 1991; Sleep and Sykes, 1993; Lenhard et al., 1995; Reinecke and Sleep, 2002; Hoeg et al., 2004). The equation for steady air flow with compressibility of air in soil is given, in a cylindrical coordinate system, by Eq. (1) (US Army Corps of Engineers, 2002) when the air permeability coefficient and the viscosity of air do not change throughout the analytical domain:

$$
\frac{\partial^{2} \psi_{\mathrm{a}}^{2}}{\partial r^{2}}+\frac{1}{r} \frac{\partial \psi_{\mathrm{a}}^{2}}{\partial r}+\frac{\partial^{2} \psi_{\mathrm{a}}^{2}}{\partial z^{2}}=0,
$$

where $\psi_{\mathrm{a}}$ is the air pressure head [L], $r$ is the radial coordinate $[\mathrm{L}]$, and $z$ is the vertical coordinate [L], which is positive in the downward direction.

The US Army Corps of Engineers (2002) developed analytical equations based on Eq. (1) that are applicable when there is (1) radial air flow toward an extraction well penetrating a permeable layer bounded on the top and bottom by impermeable layers, (2) radial air flow toward a sink point in a space without boundaries, (3) air flow toward a partly screened extraction well in a space without boundaries, (4) air flow toward a partly screened extraction well from the ground surface, or (5) air flow toward a partly screened extraction well in a permeable layer bounded by the ground surface and the groundwater table. These equations are simple and suitable for obtaining the air permeability coefficient from the results of air permeability tests. These equations are evaluated as follows:

Radial Air Flow toward an Extraction Well Penetrating a Permeable Layer with Upper and Lower Impermeable Boundaries

If an extraction well with a screen of length B [L] is installed with the center of the well at $r=0$, and air discharge, $q_{\mathrm{a}}\left[\mathrm{L}^{3} / \mathrm{T}\right]$, through the screen is constant (Fig. 1), then $\psi_{\mathrm{a}}$ is equal to the atmospheric pressure head $\psi_{\text {atm }}[\mathrm{L}]$ at $r=r_{0}$. Under these conditions Eq. (1) is solved as follows:

$$
\psi_{\mathrm{atm}}^{2}-\psi_{\mathrm{a}}^{2}=\frac{q_{\mathrm{a}} \psi_{\mathrm{atm}} \mu_{\mathrm{ra}}}{\pi B K_{\mathrm{a}}} \ln \left(r_{0} / r\right)
$$

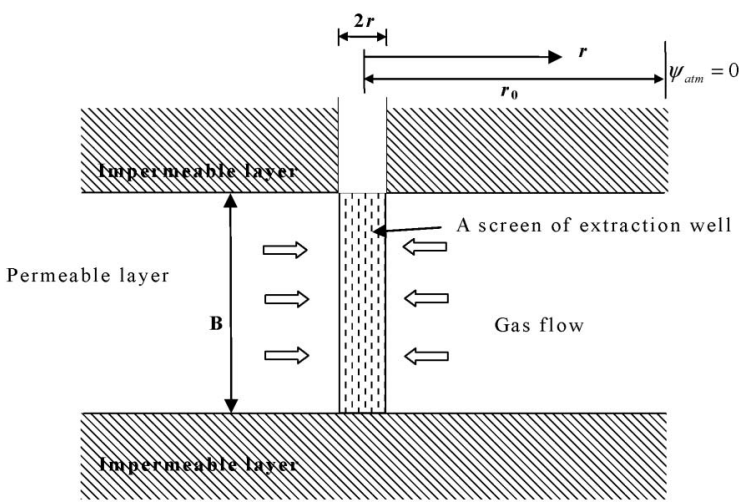

Fig. 1. The structure of an extraction well and the soil conditions around the well in cylindrical coordinates

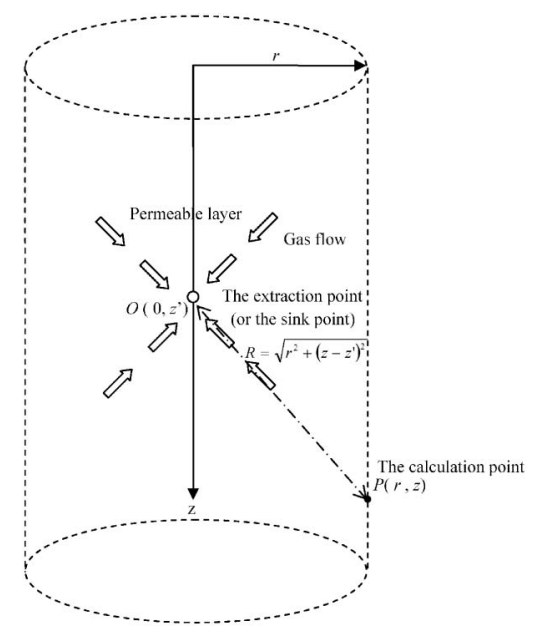

Fig. 2. Unrestricted air flow in a cylindrical coordinate system. The air pressure head is calculated at $P(r, z)$

where $K_{\mathrm{a}}$ is the air permeability coefficient [L/T] and $\mu_{\mathrm{ra}}$ is the relative viscosity of air (i.e., the ratio of the viscosity of air to that of water) [dimensionless].

\section{Radial Air Flow toward a Sink Point in a Space without Boundaries}

If air is extracted from a point at $z=z^{\prime}$ and $r=0$ in the ground (Fig. 2), the following formula can be derived in a spherical coordinate system if the effects of the ground surface and the groundwater table boundaries are ignored. $R$ in spherical coordinates is converted to the radial coordinate $r$ and the vertical coordinate $z$ in cylindrical coordinates. Air flows only toward the extraction point $O$ from the surrounding ground in this case (Shan et al., 1992)

$$
\psi_{\mathrm{atm}}^{2}-\psi_{\mathrm{a}}^{2}=\frac{q_{\mathrm{a}} \psi_{\mathrm{atm}} \mu_{\mathrm{ra}}}{2 \pi K_{\mathrm{a}} \sqrt{r^{2}+\left(z-z^{\prime}\right)^{2}}}
$$

\section{Air Flow toward a Partly Screened Extraction Well in a Space without Boundaries}

If the screen is located between an lower point $a$ and a upper point $b$ in the extraction well (Fig. 3), a solution of 


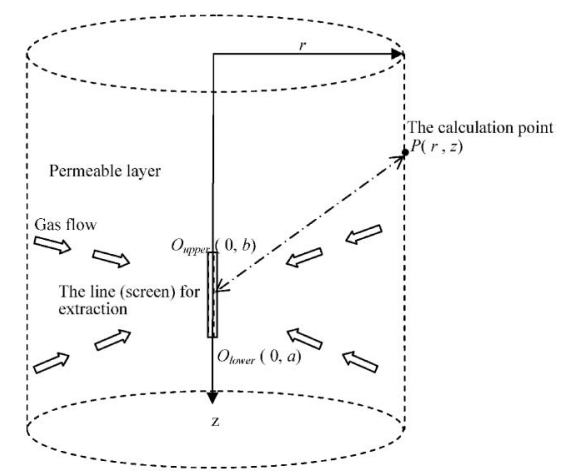

Fig. 3. Unrestricted air flow when air is extracted along a line from $O_{\text {upper }}$ to $O_{\text {lower }}$ passing through the origin of a cylindrical coordinate system $(r=0)$. The air pressure head is calculated at the point $P(r, z)$

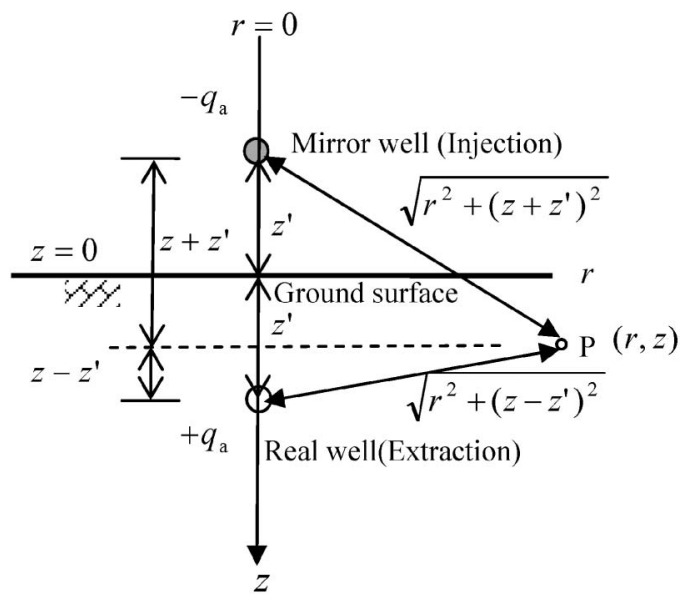

Fig. 4. The method of images applied to a well in the ground. The ground surface (thick solid line) is at $z=0$. The white circle and the gray circle at $r=0$ respectively describe a real well. The air pressure head is calculated at point $P$

Eq. (1) can be obtained by integrating Eq. (3) from $a$ to $b$, as follows (Shan et al., 1992).

$$
\psi_{\mathrm{atm}}^{2}-\psi_{\mathrm{a}}^{2}=\frac{q_{\mathrm{a}} \psi_{\mathrm{atm}} \mu_{\mathrm{ra}}}{2 \pi K_{\mathrm{a}}(a-b)} \ln \left(\frac{z-b+\sqrt{r^{2}+(z-b)^{2}}}{z-a+\sqrt{r^{2}+(z-a)^{2}}}\right) .
$$

The air flow in this case is inconsistent with that which occurs by extraction at a point because the air flow in the radial direction is faster than that in the vertical direction.

\section{Air Flow toward a Partly Screened Extraction Well from the Ground Surface}

Furthermore, a solution of Eq. (1) that takes into account the ground surface (Fig. 4) can be derived by using the method of images, as follows (Shan et al., 1992).

$$
\begin{aligned}
\psi_{\mathrm{atm}}^{2}-\psi_{\mathrm{a}}^{2}= & \frac{q_{\mathrm{a}} \psi_{\mathrm{atm}} \mu_{\mathrm{ra}}}{2 \pi K_{\mathrm{a}}(a-b)} \ln \left(\frac{z-b+\sqrt{r^{2}+(z-b)^{2}}}{z-a+\sqrt{r^{2}+(z-a)^{2}}}\right. \\
& \left.\times \frac{z+b+\sqrt{r^{2}+(z+b)^{2}}}{z+a+\sqrt{r^{2}+(z+a)^{2}}}\right) .
\end{aligned}
$$

The air pressure head should be equal to the atmospheric pressure head at the ground surface, but the air pressure head calculated by Eq. (4) does not become atmospheric pressure head. The mirror well, which is not a real well but an imaginary well, is installed in the symmetrical position above the ground surface. Air is extracted from the real well and injected into the mirror well. The condition of the ground surface is satisfied by superposing the air pressure head obtained by Eq. (4) for the real well on that obtained by Eq. (4) for the mirror well.

Air Flow toward a Partly Screened Extraction Well in a Permeable Layer Bounded by the Ground Surface and the Groundwater Table

Therefore, a solution of Eq. (1) that takes into account both the ground surface and the groundwater table can also be derived by using the above method of images, as follows (Shan et al., 1992):

$$
\begin{aligned}
\psi_{\mathrm{atm}}^{2}-\psi_{\mathrm{a}}^{2}= & \frac{q_{\mathrm{a}} \psi_{\mathrm{atm}} \mu_{\mathrm{ra}}}{2 \pi K_{\mathrm{a}}(a-b)}\left[\operatorname { l n } \left(\frac{z-b+\sqrt{r^{2}+(z-b)^{2}}}{z-a+\sqrt{r^{2}+(z-a)^{2}}}\right.\right. \\
& \left.\times \frac{z+b+\sqrt{r^{2}+(z+b)^{2}}}{z+a+\sqrt{r^{2}+(z+a)^{2}}}\right)-\sum_{n=1}^{\infty}(-1)^{n} \\
& \times \ln \left(\frac{z+a+2 n h+\sqrt{r^{2}+(z+a+2 n h)^{2}}}{z+b+2 n h+\sqrt{r^{2}+(z+b+2 n h)^{2}}}\right. \\
& \times \frac{z+a-2 n h+\sqrt{r^{2}+(z+a-2 n h)^{2}}}{z+b-2 n h+\sqrt{r^{2}+(z+b-2 n h)^{2}}} \\
& \times \frac{z-a+2 n h+\sqrt{r^{2}+(z-a+2 n h)^{2}}}{z-b+2 n h+\sqrt{r^{2}+(z-b+2 n h)^{2}}} \\
& \left.\left.\times \frac{z-a-2 n h+\sqrt{r^{2}+(z-a-2 n h)^{2}}}{z-b-2 n h+\sqrt{r^{2}+(z-b-2 n h)^{2}}}\right)\right]
\end{aligned}
$$

In addition to the condition of the ground surface described above, the method must satisfy the condition of the groundwater table. The air flux should be zero at the groundwater table, because the groundwater table restricts air flow, and the air pressure head above the groundwater table is smaller than that obtained by Eq. (5). Therefore, a mirror well from which air is extracted is installed in a symmetrical position to the groundwater table. The method of images uses iteration to satisfy both conditions of this case; the number of iterations ( $n$ in Fig. 5) and of mirror wells and reflections of the ground surface and groundwater table is increased until the air pressure head obtained by Eq. (6) converges.

The air permeability coefficient $K_{\mathrm{a}}$ is obtained using Eq. (2).

$$
K_{\mathrm{a}}=\frac{q_{\mathrm{a}} \psi_{\mathrm{atm}} \mu_{\mathrm{ra}}}{\pi B\left(\psi_{\mathrm{atm}}^{2}-\psi_{\mathrm{a}}^{2}\right) / \ln \left(r_{0} / r\right)}
$$

To obtain the air permeability coefficient using Eq. (7), an air permeability test must be conducted at an extraction well and several monitoring wells using a constant air discharge rate $q_{\mathrm{a}}$. The change in the air pressure head is measured at the monitoring wells, which are at a known distance from the extraction well. The discharge rate $q_{\mathrm{a}}$, 


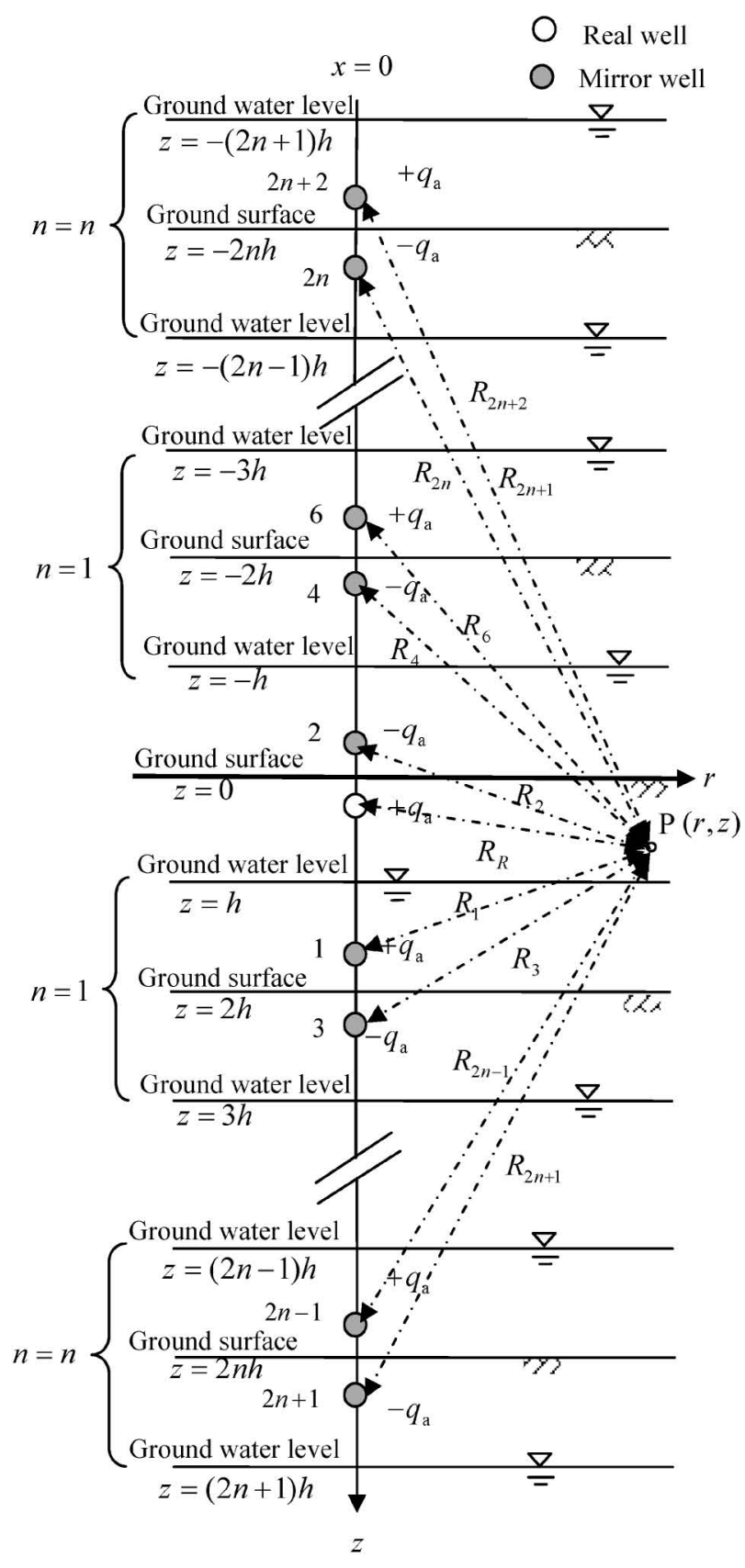

Fig. 5. The method of images applied to a well in the ground that penetrates the groundwater table. The ground surface and the groundwater table are at $z=0$ and $z=h$, respectively. The white circle and the gray circles at $\boldsymbol{r}=0$ respectively describe the real well and mirror wells. The air pressure head is calculated at point $P$

the atmospheric pressure head $\psi_{\text {atm }}$, the relative viscosity of air $\mu_{\mathrm{ra}}$, and the length of the screen in the extraction well $B$ must be known when the air permeability test is carried out. Consequently, $q_{\mathrm{a}} \psi_{\mathrm{atm}} \mu_{\mathrm{ra}} / \pi B$ is constant, and the air permeability coefficient can be obtained from Eq. (7) if $E$, which indicates the strength for velocity of air, which is equal to $\left(\psi_{\mathrm{atm}}^{2}-\psi_{\mathrm{a}}^{2}\right) / \ln \left(r_{0} / r\right)$, becomes constant for every value of $\ln \left(r_{0} / r\right)$ or some $\ln \left(r_{0} / r\right)$. Thus, $\ln \left(r_{0}\right.$ $/ r$ ) in Eq. (7) is a coefficient for distance from the extraction well. Moreover, $L_{1}, L_{2}, L_{3}$, and $L_{4}$ (defined in Eq. (8)) are the coefficients for the distance from the extrac- tion well in Eqs. (3), (4), (5) and (6), respectively. The dimension of $L_{1}$ is length, and $L_{2}, L_{3}$, and $L_{4}$ are rates representing the location of the monitoring well or the location where the air pressure head at the extraction well is calculated. These coefficients become greater in the neighborhood of the extraction well and become smaller away from the extraction well.

$$
\begin{aligned}
L_{1}= & \frac{1}{\sqrt{r^{2}+\left(z-z^{\prime}\right)^{2}}} \\
L_{2}= & \ln \left(\frac{z-b+\sqrt{r^{2}+(z-b)^{2}}}{z-a+\sqrt{r^{2}+(z-a)^{2}}}\right) \\
L_{3}= & \ln \left(\frac{z-b+\sqrt{r^{2}+(z-b)^{2}}}{z-a+\sqrt{r^{2}+(z-a)^{2}}} \times \frac{z+b+\sqrt{r^{2}+(z+b)^{2}}}{z+a+\sqrt{r^{2}+(z+a)^{2}}}\right) \\
L_{4}= & {\left[\operatorname { l n } \left(\frac{z-b+\sqrt{r^{2}+(z-b)^{2}}}{z-a+\sqrt{r^{2}+(z-a)^{2}}}\right.\right.} \\
& \left.\times \frac{z+b+\sqrt{r^{2}+(z+b)^{2}}}{z+a+\sqrt{r^{2}+(z+a)^{2}}}\right)-\sum_{n=1}^{\infty}(-1)^{n} \\
& \times \ln \left(\frac{z+a+2 n h+\sqrt{r^{2}+(z+a+2 n h)^{2}}}{z+b+2 n h+\sqrt{r^{2}+(z+b+2 n h)^{2}}}\right. \\
& \times \frac{z+a-2 n h+\sqrt{r^{2}+(z+a-2 n h)^{2}}}{z+b-2 n h+\sqrt{r^{2}+(z+b-2 n h)^{2}}} \\
& \times \frac{z-a+2 n h+\sqrt{r^{2}+(z-a+2 n h)^{2}}}{z-b+2 n h+\sqrt{r^{2}+(z-b+2 n h)^{2}}} \\
& \left.\left.\times \frac{z-a-2 n h+\sqrt{r^{2}+(z-a-2 n h)^{2}}}{z-b-2 n h+\sqrt{r^{2}+(z-b-2 n h)^{2}}}\right)\right] \\
&
\end{aligned}
$$

The gradient $E$ of the regression expression between $\psi_{\mathrm{atm}}^{2}-\psi_{\mathrm{a}}^{2}$ and the coefficient for distance $L_{1}, L_{2}, L_{3}$, or $L_{4}$ can be defined as follows:

$$
E=\left(\psi_{\mathrm{atm}}^{2}-\psi_{\mathrm{a}}^{2}\right) / L_{i},
$$

where $L_{i}$ is $L_{1}$ if Eq. (3), $L_{2}$ if Eq. (4), $L_{3}$ if Eq. (5), and $L_{4}$ if Eq. (6).

By substituting the gradient $E$ in Eq. (9) or $E=\psi_{\text {atm }}^{2}-$ $\psi_{\mathrm{a}}^{2} / \ln \left(r_{0} / r\right)$ into Eqs. (2) to (6) and rearranging, the air permeability coefficient can be solved as follows:

$$
\begin{array}{ll}
K_{\mathrm{a}}=q_{\mathrm{a}} \psi_{\mathrm{atm}} \mu_{\mathrm{ra}} / \pi B E & \text { if } \quad(2) \\
K_{\mathrm{a}}=q_{\mathrm{a}} \psi_{\mathrm{atm}} \mu_{\mathrm{ra}} / 2 \pi E & \text { if } \quad(3) \\
K_{\mathrm{a}}=q_{\mathrm{a}} \psi_{\mathrm{atm}} \mu_{\mathrm{ra}} / 2 \pi(a-b) E & \text { if } \quad(4),(5), \text { or }(6) .
\end{array}
$$

Figure 6 shows the process for the calculation of the air permeability coefficient. $q_{\mathrm{a}}$ and the extraction point $z$ or the lower and upper depths of the extraction well screen (points $a$ and $b$, respectively) are decided when the air permeability test is designed (Fig. 6). $\psi_{\text {atm }}$ is measured with a barometer, and $\mu_{\mathrm{ra}}$ is obtained from the temperature measured during the air permeability test. $E$ in Eq. (9) can be obtained from the relationship between $\psi_{\text {atm }}^{2}-$ $\psi_{\mathrm{a}}^{2}$ measured during the air permeability test, and $L_{i}$ for the distance from the extraction well is calculated from the relative positions of the extraction well and a monitoring well (Fig. 6). The air permeability coefficient can be calculated using Eq. (10) if $E$ in Eq. (9) is indepen- 


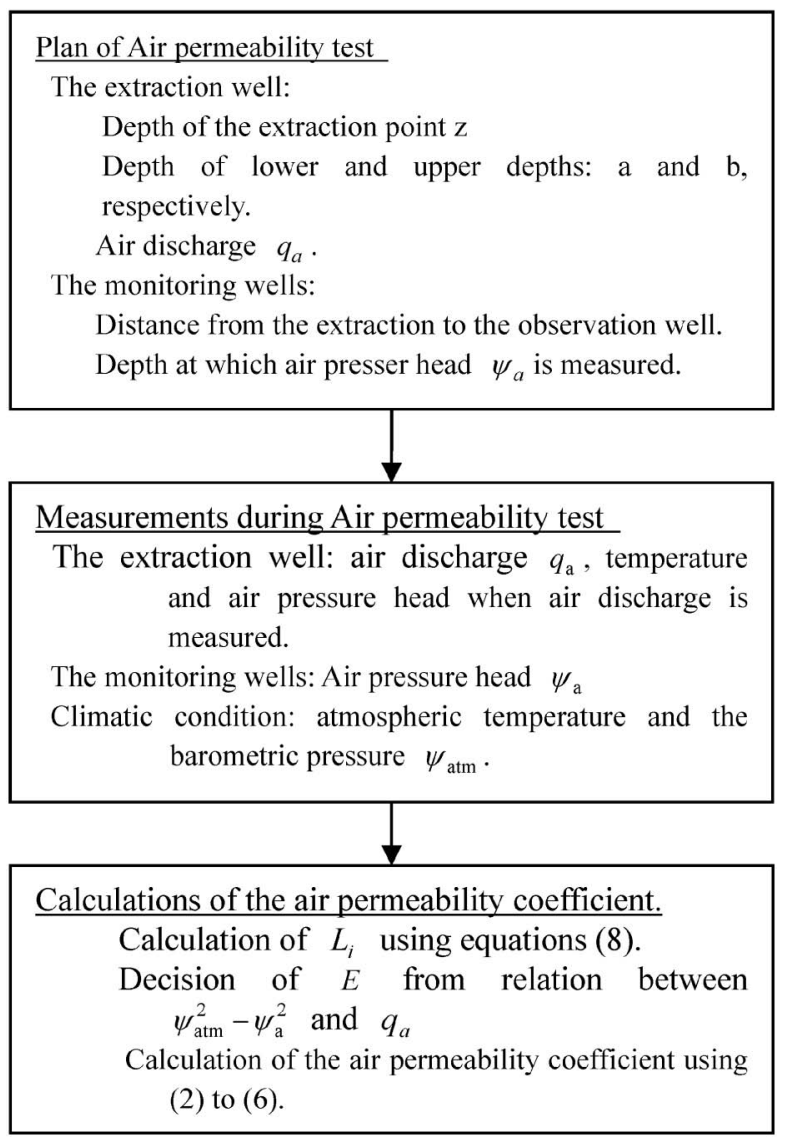

Fig. 6. The process for calculation of the air permeability coefficient

dent of $L_{i}$ in each Eq. (10). If $E$ is dependent on $L_{i}$, then the air permeability coefficient changes with $L_{i}$ and the air permeability coefficient cannot be determined. $\psi_{\mathrm{atm}}^{2}-\psi_{\mathrm{a}}^{2}$ (Eqs. (2) to (6)) should remain proportional to $\ln \left(r_{0} / r\right)$, $L_{1}, L_{2}, L_{3}$, or $L_{4}$ (Eq. (8)) provided that the air permeability coefficient is uniform over the analytical domain. However, this coefficient does not remain uniform in reality. The air permeability coefficient correlates with degree of water saturation, increasing with a decreasing degree of water saturation, and the degree of water saturation is at a minimum close to the ground surface and increases with depth in actual ground. Therefore, the air permeability coefficient reaches a maximum close to the ground surface where the degree of water saturation is at a minimum, decreases with depth from the ground surface, and becomes zero at the groundwater level, where the maximum degree of water saturation is reached. Nevertheless, previous studies have not proved that $E$ is not dependent on $\ln \left(r_{0} / r\right), L_{1}, L_{2}, L_{3}$, or $L_{4}$ in actual ground. It is therefore important to clarify the relationships between $E$ and $\ln \left(r_{0} / r\right), L_{1}, L_{2}, L_{3}$, and $L_{4}$ in the field. This study aimed to find these relationships and the applicable conditions necessary to reproduce field conditions with variable or uniform degree of water saturation from simulation results and air permeability test results for five sites. The results showed that the air permeability coefficient could be calculated using $\ln \left(r_{0} / r\right), L_{1}, L_{2}, L_{3}$, or $L_{4}$, and $\psi_{\mathrm{atm}}^{2}-\psi_{\mathrm{a}}^{2}$ measured in monitoring wells, which is proportional to $\ln \left(r_{0} / r\right), L_{1}, L_{2}, L_{3}$, or $L_{4}$ within every range or some range of these coefficients.

\section{ESTIMATION OF THE GRADIENT $E$ AND THE AIR PERMEABILITY COEFFICIENT USING A FINITE-ELEMENT METHOD FOR AIR-WATER TWO-PHASE FLOW WITH COMPRESSION OF AIR IN SOIL}

In the present model, numerical simulations (Celia and Bouloutas, 1990; Hibi et al., 2001) are carried out using the Galerkin Finite Element Method (GFEM) for porous media to estimate the gradient $E$ and the air permeability coefficient from calculated values of $\psi_{\mathrm{atm}}^{2}-\psi_{\mathrm{a}}^{2}$ and $\ln \left(r_{0} /\right.$ $r$ ), $L_{1}, L_{2}, L_{3}$, and $L_{4}$. The gradient $E$ is evaluated when the degree of water saturation of the ground varies with depth and also when it is essentially uniform. The uniform air permeability coefficient without degree of water saturation is defined on the basis of the conditions assumed for the derivation of Eqs. (2) to (6) from Eq. (1). The variable air permeability coefficient with degree of water saturation, however, differs from that of Eqs. (2) to (6).

Numerical Model for Air-water Two-phase Flow Taking into Account the Compression of Air in Soil

Equation (11a) describes steady air flow, and Eq. (11b) describes steady water flow. Both equations are derived from Darcy's law and the law of conservation of mass for the air or water phase in soil in a cylindrical coordinate system.

$$
\begin{aligned}
& \frac{\partial}{\partial r}\left(\frac{\psi_{\mathrm{a}} \rho_{\mathrm{atm}}}{\psi_{\mathrm{atm}}} \frac{k_{\mathrm{ra}} K_{\mathrm{s}}}{\mu_{\mathrm{ra}}} \frac{\partial \psi_{\mathrm{a}}}{\partial r}\right)+\frac{1}{r} \frac{\psi_{\mathrm{a}} \rho_{\mathrm{atm}}}{\psi_{\mathrm{atm}}} \frac{k_{\mathrm{ra}} K_{\mathrm{s}}}{\mu_{\mathrm{ra}}} \frac{\partial \psi_{\mathrm{a}}}{\partial r} \\
& \quad+\frac{\partial}{\partial z}\left(\frac{\psi_{\mathrm{a}} \rho_{\mathrm{atm}}}{\psi_{\mathrm{atm}}} \frac{k_{\mathrm{ra}} K_{\mathrm{s}}}{\mu_{\mathrm{ra}}} \frac{\partial}{\partial z}\left(\psi_{\mathrm{a}}-\rho_{\mathrm{ra}} z\right)\right)=0 \\
& \frac{\partial}{\partial r}\left(k_{\mathrm{rw}} K_{\mathrm{s}} \frac{\partial \psi_{\mathrm{w}}}{\partial r}\right)+\frac{k_{\mathrm{rw}} K_{\mathrm{s}}}{r} \frac{\partial \psi_{\mathrm{w}}}{\partial r} \\
& \quad+\frac{\partial}{\partial z}\left[k_{\mathrm{rw}} K_{\mathrm{s}} \frac{\partial}{\partial z}\left(\psi_{\mathrm{w}}-z\right)\right]=0,
\end{aligned}
$$

where $\rho_{\text {ra }}$ is the relative density (i.e., the ratio of the density of air to that of water) [dimensionless] of air, $\rho_{\text {atm }}$ is the density $\left[\mathrm{M} / \mathrm{L}^{3}\right]$ of air when the air pressure is equal to the atmospheric pressure head, $k_{\mathrm{ra}}$ is the relative air permeability coefficient (i.e., the ratio of the air permeability coefficient to the saturated hydraulic conductivity) [dimensionless], $k_{\mathrm{rw}}$ is the relative hydraulic conductivity (i.e., the ratio of the hydraulic conductivity of the water phase to the saturated hydraulic conductivity) [dimensionless], $K_{\mathrm{s}}$ is the saturated hydraulic conductivity $[\mathrm{L} / \mathrm{T}]$, and $\psi_{\mathrm{w}}$ is the water pressure head [L]. Equations (11) are formulated using the GFEM in this numerical simulation (Hibi et al., 2001). Because the curve between the degree of water saturation and the capillary pressure head for water and air generally became continuous at the degree of water saturation 1.0 (Davis, 1994), the van Genuchten (1980) and Burdine (1953) was applied in the present simulations to the constitutive equation be- 
tween degree of water saturation and capillary pressure head as follows:

$$
\bar{S}_{\mathrm{w}}=\frac{S_{\mathrm{w}}-S_{\mathrm{rw}}}{1-S_{\mathrm{rw}}-S_{\mathrm{ra}}}=\left\{1+\left(\alpha \psi_{\mathrm{aw}}\right)^{\beta}\right\}^{-\gamma}
$$

where $S_{\mathrm{w}}$ is degree of water saturation (i.e., the ratio of the volume of water to that of voids in soil) [dimensionless], $\alpha$ and $\beta$ are the Van Genuchten parameters ( $\alpha$ is the reciprocal $\left[\mathrm{L}^{-1}\right]$ of the entry pressure head, and $\beta$ is a parameter [-] describing the pore space geometry of the soil), $\gamma$ is $[1-1 / \beta], S_{\mathrm{rw}}$ is the residual degree of water saturation (i.e., the ratio of the volume of the residual water to that of the voids in soil) [dimensionless], $S_{\mathrm{ra}}$ is the residual degree of air saturation (i.e., the ratio of the volume of the residual air to that of the voids in soil) [dimensionless], $\bar{S}_{\mathrm{w}}$ is the effective degree of water saturation [dimensionless], and $\psi_{\text {aw }}$ is the capillary pressure head [L] between water and air.

The Burdine model is also applied to the constitutive equations between degree of water saturation and the relative air permeability coefficient or the relative hydraulic conductivity, as follows:

$$
\begin{aligned}
& k_{\mathrm{rw}}=\bar{S}_{\mathrm{w}}^{2}\left\{1-\left(1-\bar{S}_{\mathrm{w}}^{1 / \gamma}\right)^{\gamma}\right\} \\
& k_{\mathrm{ra}}=\left(1-\bar{S}_{\mathrm{w}}\right)^{2}\left(1-\bar{S}_{\mathrm{w}}^{1 / \gamma}\right)^{\gamma}
\end{aligned}
$$

The precision of this numerical simulation was validated by comparing the air pressure head determined by this simulation with the air pressure head calculated by Eq. (2). The air pressure head obtained by this simulation was consistent with that of Eq. (2) (Hibi et al., 2006b).

\section{Modeling and Discretization for Numerical Simulation}

Figure 7 shows the analytical domain and boundary conditions for the numerical simulation. The geometrical outline of the analytical domain is a rectangle, and the extent of the domain is $0.05 \mathrm{~m} \leq r \leq 100 \mathrm{~m}$ and $0 \mathrm{~m} \leq z \leq 65$ $\mathrm{m}$. In the GFEM numerical simulation, a total of 1435 quadrangular elements with nodal spacing of 0.20 to 5.0 $\mathrm{m}$ in the radial direction and 0.25 to $5.00 \mathrm{~m}$ in the vertical direction are used and the analytical domain is discretized with $36 \times 42=1512$ nodes. The nodes in the neighborhood of the extraction well (in the range of 0.05 $\mathrm{m} \leq r \leq 10.00 \mathrm{~m}$ ) are 0.20 to $0.5 \mathrm{~m}$ apart in the radial direction. The space between nodes increases with distance from the extraction well. The nodes in the neighborhood of the screen in the extraction well are finely spaced in the vertical direction: $0.25 \mathrm{~m}$ apart in the range of $4.50 \mathrm{~m} \leq z \leq 5.50 \mathrm{~m}$. It has been shown that the air pressure head obtained by the simulations is not improved if the simulations are carried out with finer nodal spacing (Hibi et al., 2006a).

In the model, a 0.5 -m-long screen is placed in an extraction well from $z=4.75$ to $5.25 \mathrm{~m}$ at $r_{0}=0.05 \mathrm{~m}$. The air discharge is $0.06 \mathrm{~m}^{3} / \mathrm{min}$. The domain radius, equal to $100 \mathrm{~m}$, is sufficiently large and the domain boundary is sufficiently far from the extraction well that the assigned boundary conditions do not influence the air pressure head distribution in the domain. The air pressure head assigned at the boundary is equal to an atmospheric pressure head $\psi_{\mathrm{a}}=10.34 \mathrm{~m}$. The assigned discharge rate $q_{\mathrm{a}}$ of air at $r_{0}=0.05 \mathrm{~m}$, excluding the depth from $z=4.75$ to $5.25 \mathrm{~m}$, is $0 \mathrm{~m}^{3} / \mathrm{min}$. The ground surface is permeable, and the assigned air pressure head at the ground surface, $z=0 \mathrm{~m}$, is equal to an atmospheric pressure head $\psi_{\mathrm{a}}=$ $10.34 \mathrm{~m}$. On the other hand, the assigned discharge rate of water is $q_{\mathrm{w}}=0 \mathrm{~m}^{3} / \mathrm{min}$ at the ground surface because the ground surface is impermeable to water. An impermeable layer in the vertical direction is at $z=65 \mathrm{~m}$. The discharge rate of air $q_{\mathrm{a}}$ and the discharge rate of water $q_{\mathrm{w}}$ at $z=65 \mathrm{~m}$ are both equal to zero. The water pressure head $h_{\mathrm{wL}}$ at the left boundary of the analytical domain, where the radial coordinate is $r_{0}=0.05 \mathrm{~m}$, is equal to the water pressure head $h_{\mathrm{wR}}$ at the right boundary of the analytical domain, where the radial coordinate is $r=100 \mathrm{~m}$, and these water pressure heads are assigned the value 3.34

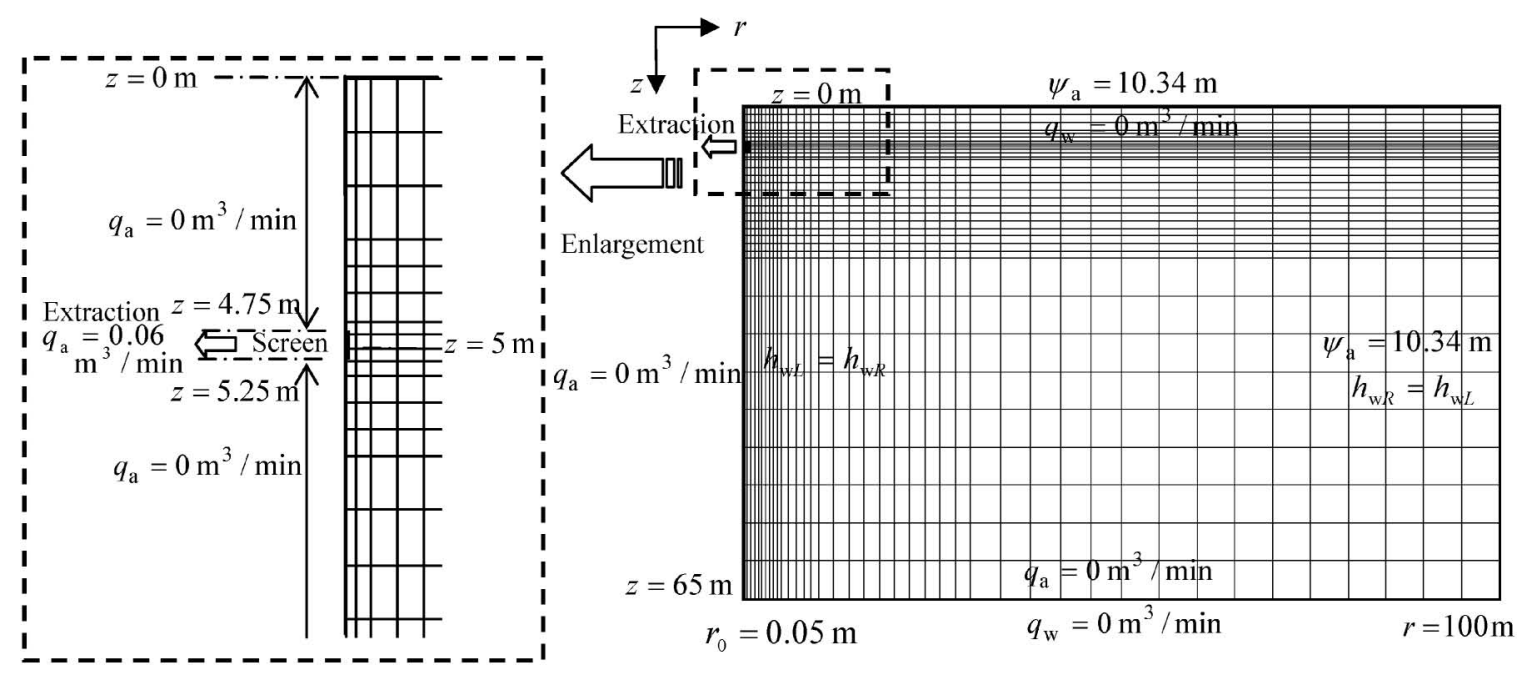

Fig. 7. The analytical domain and boundary conditions for simulations by the finite-element method for air-water two-phase flow in the soil. The whole analytical domain and the boundary conditions for the air pressure head $\psi_{\mathrm{a}}$, the water pressure head $h_{\mathrm{w}}$, and the fluxes of air $q_{\mathrm{a}}$ and water $q_{\mathrm{w}}$, are shown on the right 
$\mathrm{m}$ when the simulation is carried out with $\psi_{\mathrm{aw}}-k_{\mathrm{ra}}-S_{\mathrm{w}}$ curve No. 1 to reproduce the distribution of variable water saturation, and the value $0.34 \mathrm{~m}$ with $\psi_{\mathrm{aw}}-k_{\mathrm{ra}}-S_{\mathrm{w}}$ curve No. 2 to reproduce the distribution of uniform degree of water saturation. Therefore, the groundwater table is at ground level GL-7 $\mathrm{m}$ in the simulation using $\psi_{\text {aw }}$ $-k_{\mathrm{ra}}-S_{\mathrm{w}}$ curve No. 1 , and at GL-10 $\mathrm{m}$ in the simulation using $\psi_{\mathrm{aw}}-k_{\mathrm{ra}}-S_{\mathrm{w}}$ curve No. 2 from atmospheric pressure head at the ground surface and the water pressure head at $r_{0}=0.05 \mathrm{~m}$ and $r=100 \mathrm{~m}$.

\section{Parameters Used in the Numerical Simulation}

Assumptions are made for sandy soil in order to carry out the numerical simulation to reproduce the conditions for air permeability tests carried out in sandy soils. Reasonable normal values for the saturated hydraulic conductivity and porosity for sand (Table 1) are therefore used in these simulations. A saturated hydraulic conductivity of $1.0 \times 10^{-3} \mathrm{~cm} / \mathrm{s}$ and a porosity of 0.4 are assumed. The densities and the viscosity of water are assumed to $1.0 \mathrm{~g} / \mathrm{cm}^{3}$ and $1.0 \times 10^{-3} \mathrm{~Pa} \mathrm{~s}$, respectively, and the density and viscosity of air are assumed to $0.012 \mathrm{~g} /$ $\mathrm{cm}^{3}$ and $1.8 \times 10^{-5} \mathrm{~Pa} \mathrm{~s}$, respectively. Numerical simulations were conducted to estimate the gradient $E$ between $\psi_{\mathrm{atm}}^{2}-\psi_{\mathrm{a}}^{2}$ and $\ln \left(r_{0} / r\right), L_{1}, L_{2}, L_{3}$, and $L_{4}$ under the assumption that the degree of water saturation varied with

Table 1. Soil and fluid parameters used in the numerical simulation by the finite-element method for air-water two-phase flow in soil

\begin{tabular}{|c|c|c|c|c|c|}
\hline \multirow{2}{*}{$\begin{array}{c}\text { Saturated } \\
\text { hydraulic } \\
\text { conductivity } \\
k_{\mathrm{s}}(\mathrm{cm} / \mathrm{s})\end{array}$} & \multirow[t]{2}{*}{ Porosity } & \multicolumn{2}{|c|}{ Water } & \multicolumn{2}{|c|}{ Air } \\
\hline & & $\begin{array}{c}\text { Density } \\
\rho_{\mathrm{w}}\left(\mathrm{g} / \mathrm{cm}^{3}\right)\end{array}$ & $\begin{array}{l}\text { Viscosity } \\
\mu_{\mathrm{w}}(\mathrm{Pa} \cdot \mathrm{S})\end{array}$ & $\begin{array}{c}\text { Density } \\
\rho_{\mathrm{a}}\left(\mathrm{g} / \mathrm{cm}^{3}\right)\end{array}$ & $\begin{array}{l}\text { Viscosity } \\
\mu_{\mathrm{a}}(\mathrm{Pa} \cdot \mathrm{S})\end{array}$ \\
\hline $1.0 \times 10^{-3}$ & 0.4 & 1 & $1.0 \times 10^{-3}$ & 0.012 & $1.8 \times 10^{-5}$ \\
\hline
\end{tabular}

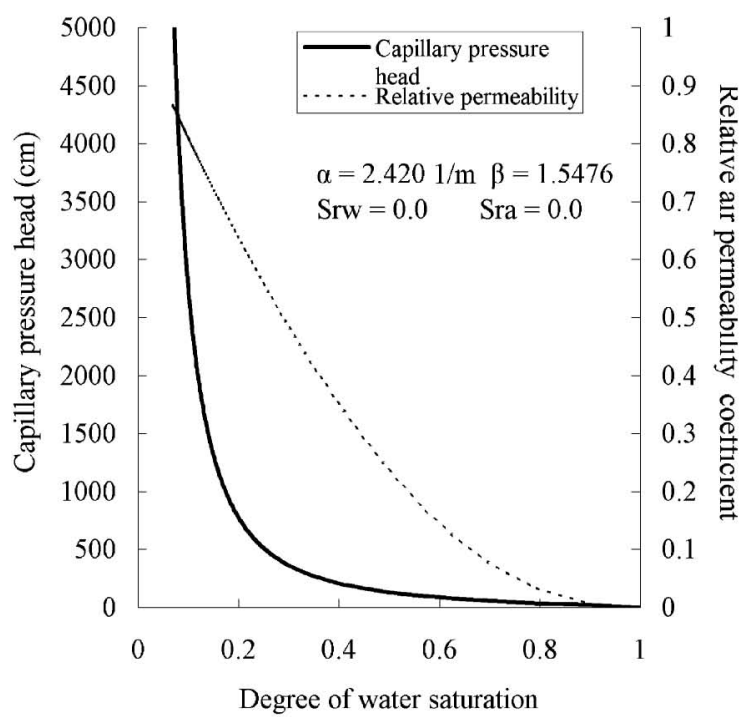

(a) $\psi_{\text {aw }}-k_{\text {ra }}-S_{\mathrm{w}}$ curve No.1 depth, whereas the analytical solution assumes that the degree of water saturation is uniform everywhere in the analytical domain. Therefore, in the numerical simulations, the air permeability coefficient varies with respect to the spatial coordinate, whereas the air permeability coefficient is uniform in the analytical solution. The simulations using $\psi_{\mathrm{aw}}-k_{\mathrm{ra}}-S_{\mathrm{w}}$ curve No. 1 was carried out due to reproduce the sandy ground that the degree of water saturation may have been varied with depth from the ground surface (Fig. 8(a)), whereas the simulations using $\psi_{\mathrm{aw}}-k_{\mathrm{ra}}-S_{\mathrm{w}}$ curve No. 2 was carried out due to reproduce the sandy ground that the degree of water saturation was uniform in the vapor zone except near the groundwater table (Fig. 8(b)). Then these van Genuchten parameters were assumed for the reproduction of the sandy ground with the uniform degree of water saturation and the sandy ground with the varied degree of water saturation.

The air and water parameter values used in the simulations are shown in Table 1 . The density of air is approximately $1 \%$ that of water, and the effect of gravity is neglected. The viscosity of water is approximately 50 times that of air; consequently, the air permeability coefficient would be larger than the hydraulic conductivity by two orders of magnitude.

\section{Estimation of the Gradient $E$ from the Results of the $\mathrm{Nu}$ - merical Simulation}

The distribution of degree of water saturation was obtained by numerical simulations using the finite-element method for air-water two-phase flow in soil for $\psi_{\text {aw }}-k_{\text {ra }}$ $-S_{\mathrm{w}}$ curves No. 1 (Fig. 9(a)) and No. 2 (Fig. 9(b)). With curve No. 1 , the degree of water saturation exceeds 0.2 at the ground surface and rises to roughly 0.8 near the extraction well screen as a result of air extraction from the

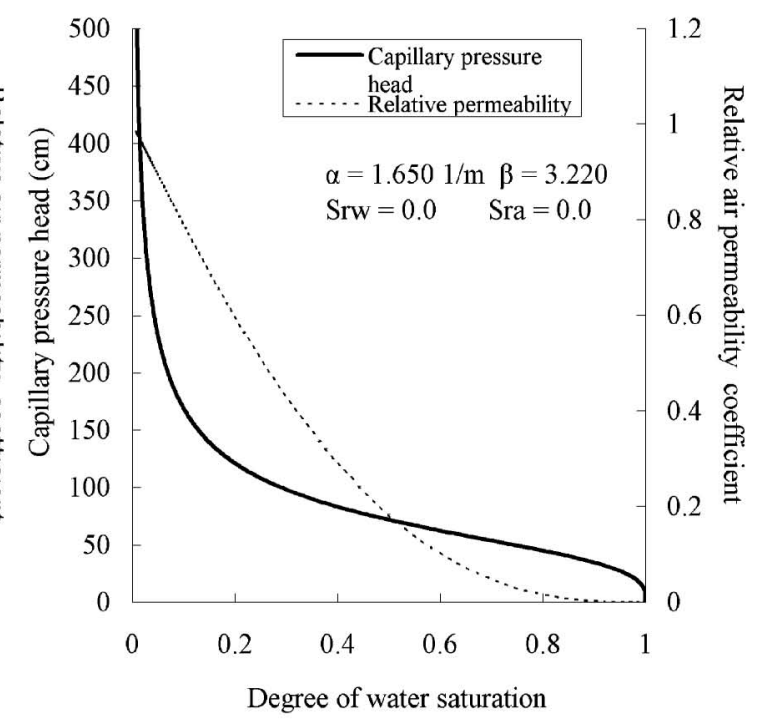

(b) $\psi_{\text {aw }}-k_{\mathrm{ra}}-S_{\mathrm{w}}$ curve No.2

Fig. 8. Soil-water characteristic curves $\left(\psi_{\mathrm{aw}}-S_{\mathrm{w}}\right)$ and the relationships between the relative permeability of air and degree of water saturation $\left(k_{\mathrm{ra}}\right.$ $\left.-S_{w}\right)$ used in the numerical simulations by the finite-element method for air-water two-phase flow in soil 


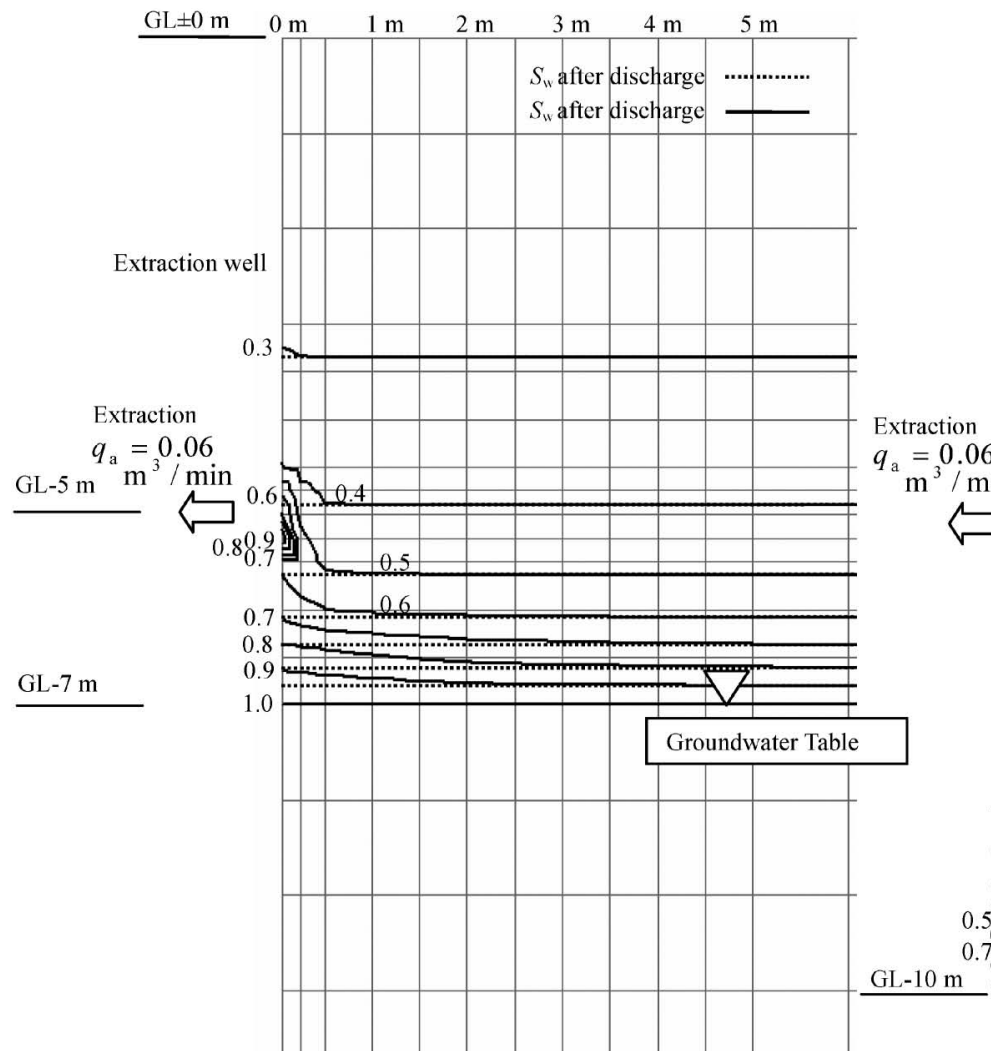

(a) A case of soil with $\psi_{\mathrm{aw}}-k_{\mathrm{ra}}-S_{\mathrm{w}}$ curve No.1

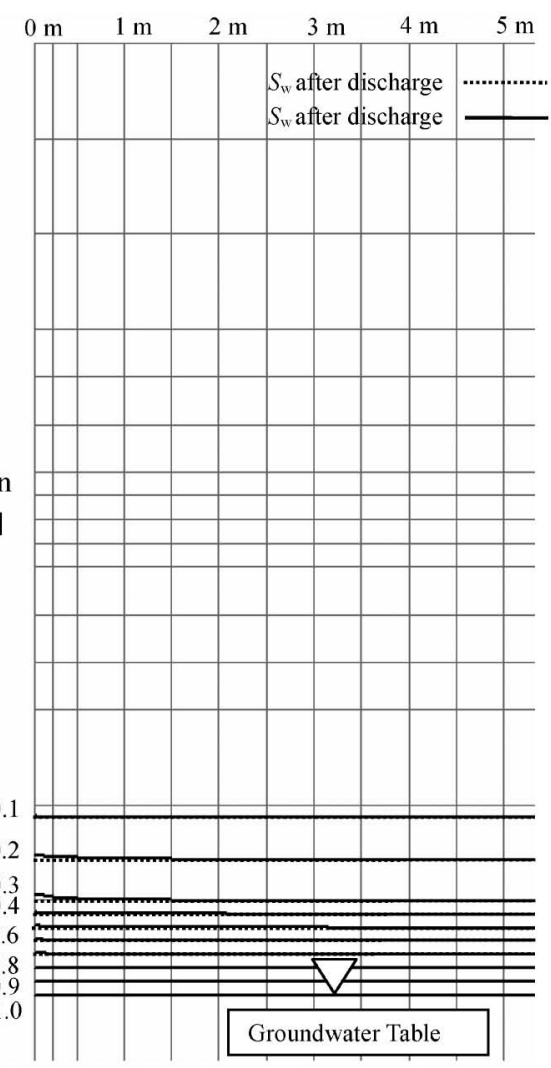

(b) A case of soil with $\psi_{\text {aw }}-k_{\text {ra }}-S_{\mathrm{w}}$ curve No.2

Fig. 9. Distributions of water saturation obtained with the finite-element method for air-water two-phase flow in soil using $\psi_{\mathrm{aw}}-\boldsymbol{k}_{\mathrm{ra}}-S_{\mathrm{w}}$ curve No. 1 (a) and No. 2 (b). Gray lines show the mesh for the finite-element method, and the thick black lines are the contours of water saturation

screen (Fig. 9(a)). On the other hand, with curve No. 2, the degree of water saturation is apparently uniform close to the screen of the extraction well.

Figures 10(a) and (b) show the distributions of the air pressure head corresponding to the degree of water saturation distributions shown in Figs. 9(a) and (b), respectively. The air pressure head obtained by the numerical simulation with $\psi_{\mathrm{aw}}-k_{\mathrm{ra}}-S_{\mathrm{w}}$ curve No. 1 decreases gradually from the atmospheric pressure head, $10.34 \mathrm{~m}$, to $10.15 \mathrm{~m}$ directly above the groundwater table in the neighborhood of the extraction well (Fig. 10(a)). This indicates that the groundwater table influences the distribution of air pressure when air is extracted from the extraction well. On the other hand, the air pressure head obtained by the numerical simulation with $\psi_{\mathrm{aw}}-k_{\mathrm{ra}}-S_{\mathrm{w}}$ curve No. 2 decreases from 10.34 to $10.30 \mathrm{~m}$ directly above the groundwater table (Fig. 10(b)); this rate of decrease is thus smaller than that obtained by the numerical simulation using $\psi_{\mathrm{aw}}-k_{\mathrm{ra}}-S_{\mathrm{w}}$ curve No. 1 . These results suggest that the groundwater table does not influence the distribution of the air pressure head.

The distance from the extraction well at which the air pressure head approaches $10.30 \mathrm{~m}$ in the radial direction is $4.4 \mathrm{~m}$ for curve No. 1 and $3.0 \mathrm{~m}$ for curve No. 2 (Fig. 10 (a) and (b), respectively). The radius of vacuum influence in ground with $\psi_{\mathrm{aw}}-k_{\mathrm{ra}}-S_{\mathrm{w}}$ curve No. 2, in which the air pressure head decreases as air is extracted, is lower than that in ground with $\psi_{\mathrm{aw}}-k_{\mathrm{ra}}-S_{\mathrm{w}}$ curve No. 1 . This difference in the radius of vacuum influence results from degree of water saturation close to the extraction well in the case of $\psi_{\mathrm{aw}}-k_{\mathrm{ra}}-S_{\mathrm{w}}$ curve No. 1 . The radius of vacuum influence is larger when the air permeability coefficient is lower, which occurs where the degree of water saturation is greater close to the extraction well and the groundwater table (Fig. 10). Since the contour lines of the air pressure head in Fig. 10(b) are concentric semicircles at the screen, the boundary conditions assigned to the numerical simulation for air-water two-phase flow in soil are similar to those assumed for Eq. (5). On the other hand, the contour lines in Fig. 10(a) are not regular concentric semicircles because the groundwater table and the ground surface obstruct the air flow. Therefore, the boundary conditions used in the numerical simulation satisfy those assumed for Eq. (6).

Figure 11 shows the relationships between $\psi_{\mathrm{atm}}^{2}-\psi_{\mathrm{a}}^{2}$ and $\ln \left(r_{0} / r\right), L_{1}, L_{2}, L_{3}$, and $L_{4}$ at $z=5 \mathrm{~m}$, at the center of the screen in the extraction well. Although $\psi_{\mathrm{atm}}^{2}-\psi_{\mathrm{a}}^{2}$ increases with $\ln \left(r_{0} / r\right)$, the increase is not linear with respect to $\ln \left(r_{0} / r\right)$ (Fig. 11).

This nonlinearity is caused by a different between the upper boundary condition of the analytical and that of numerical domain. Air flow is restricted and the air pres- 


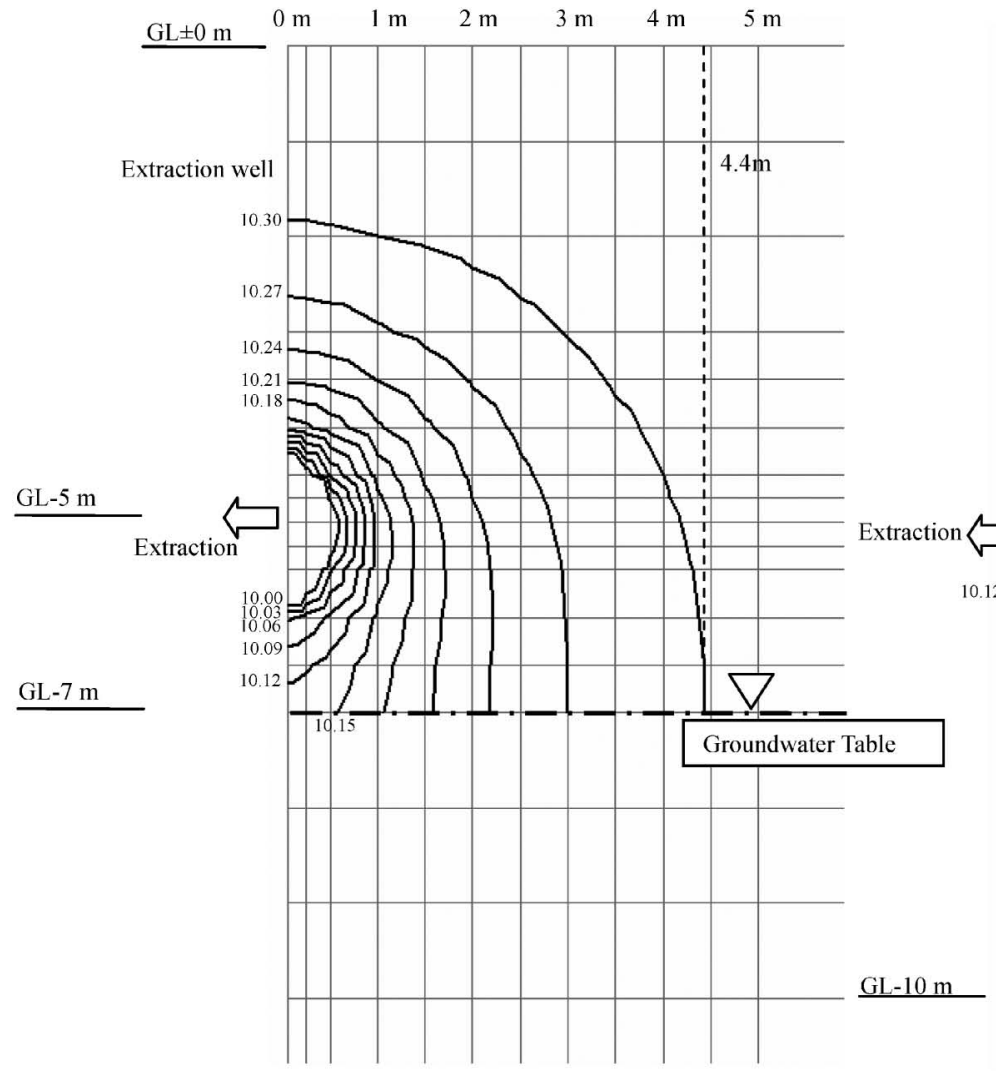

(a) A case of soil with $\psi_{\mathrm{aw}}-k_{\mathrm{ra}}-S_{\mathrm{w}}$ curve No.1

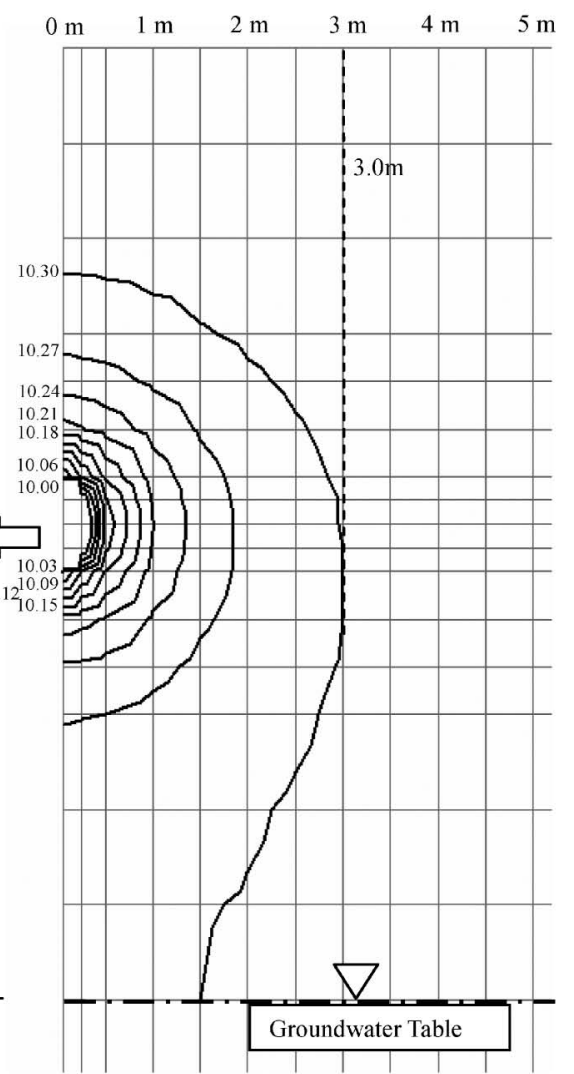

(b) A case of soil with $\psi_{\text {aw }}-k_{\text {ra }}-S_{\mathrm{w}}$ curve No.2

Fig. 10. Distributions of the air pressure head obtained with the finite element method for air-water two-phase flow in soil using $\psi_{\mathrm{aw}}-k_{\mathrm{ra}}-S_{\mathrm{w}}$ curve No. 1 (a) and No. 2 (b). Gray lines show the mesh for the finite-element method, and the thick black lines are the contours of the air pressure head (in meters)
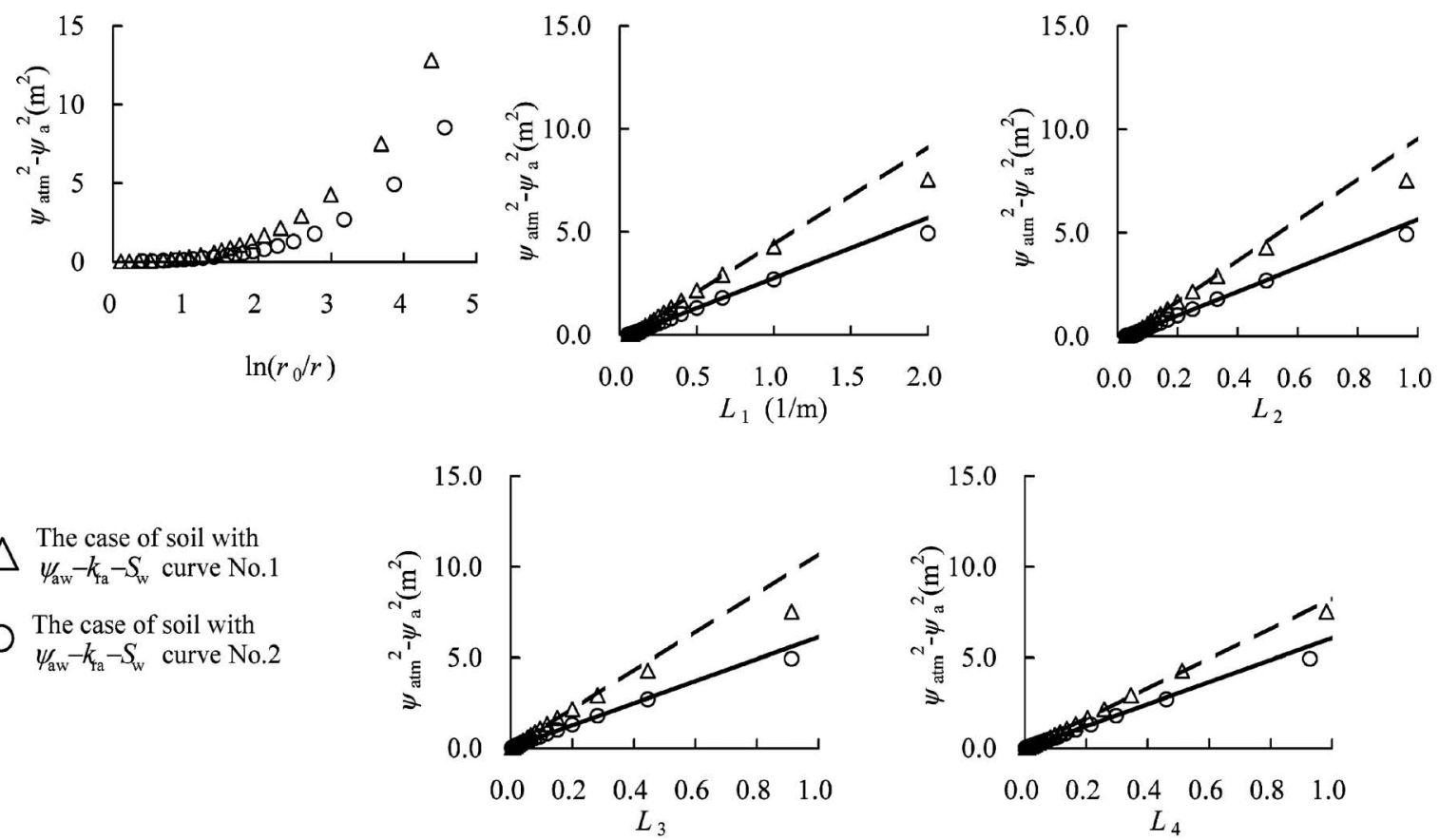

Fig. 11. The relationships between $\psi_{\mathrm{atm}}^{2}-\psi_{\mathrm{a}}^{2}$ obtained by the simulations and $\ln \left(r / r_{0}\right), L_{1}, L_{2}, L_{3}$, and $L_{4}$, coefficients for distance from the extraction well 
sure head is varied on the upper boundary of analytical domain, but the air pressure head is equal to atmospheric pressure head and air flow is permitted on the upper boundary of numerical domain.

Therefore, the air permeability coefficient cannot be obtained from the relationship between $\psi_{\mathrm{atm}}^{2}-\psi_{\mathrm{a}}^{2}$ and $\ln$ $\left(r_{0} / r\right)$. On the other hand, $\psi_{\mathrm{atm}}^{2}-\psi_{\mathrm{a}}^{2}$ is proportional to $L_{1}$ for $L_{1}$ less than 1.0 (Fig. 11). The air permeability coefficient can thus be calculated from the gradient $E$ of the regression expression between $\psi_{\mathrm{atm}}^{2}-\psi_{\mathrm{a}}^{2}$ and $L_{1}$ where $L_{1}$ does not exceed 1.0. Similarly, the gradient $E$ can be obtained from the numerical solution by the finite-element method for $L_{2}, L_{3}$, and $L_{4}$ less than $0.4,0.3$, and 0.6, respectively (Fig. 11) with a high correlation coefficient of approximately 1.0. $\psi_{\mathrm{atm}}^{2}-\psi_{\mathrm{a}}^{2}$ is not proportional to $L_{1}, L_{2}, L_{3}$, or $L_{4}$ in the neighborhood of the extraction well for two reasons: (1) the air pressure head obtained analytically with Eqs. (3) to (6) is not assigned at the extraction well, while the air pressure head used in the simulations satisfies the specified boundary condition at the extraction well, and (2) the air permeability coefficient obtained with the simulations becomes smaller as the degree of water saturation increases close to the extraction well. The analytical solutions of Eqs. (3) to (6) are derived under the assumption that the air permeability coefficient is uniform in the analytical domain.

Tables 2 and 3 list the air permeability coefficients calculated from the gradient $E$ of the regression expressions obtained by the simulations of air-water two-phase flow in soil with $\psi_{\text {aw }}-k_{\mathrm{ra}}-S_{\mathrm{w}}$ curves No. 1 and No. 2, respectively (Fig. 11). Since the correlation coefficient of the regression expression is approximately 1.0 in each case (Table 2), the value of $\psi_{\mathrm{atm}}^{2}-\psi_{\mathrm{a}}^{2}$ obtained by the numerical simulation with $\psi_{\mathrm{aw}}-k_{\mathrm{ra}}-S_{\mathrm{w}}$ curve No. 1 correlates with $L_{1}, L_{2}, L_{3}$, and $L_{4}$. The air permeability coefficients calculated from gradient $E$ shown in Table 2 are different from that used in the numerical simulation. The largest difference is that between the air permeability coefficient used in the simulation and that obtained from gradient $E$ between $\psi_{\mathrm{atm}}^{2}-\psi_{\mathrm{a}}^{2}$ and $L_{4}$; the air permeability coefficient obtained using gradient $E$ between $\psi_{\text {atm }}^{2}-\psi_{\text {a }}^{2}$ and $L_{4}$ is approximately twice as large as that used in the numerical simulation. The difference in the air permeability coefficient obtained using gradient $E$ between $\psi_{\mathrm{atm}}^{2}-\psi_{\mathrm{a}}^{2}$ and $L_{4}$ is approximately 1.2 to 1.3 times that obtained using gradient $E$ between $\psi_{\text {atm }}^{2}-\psi_{\mathrm{a}}^{2}$ and $L_{2}$ or $L_{3}$.

On the other hand, the correlation coefficients between $\psi_{\mathrm{atm}}^{2}-\psi_{\mathrm{a}}^{2}$ and $L_{1}, L_{2}, L_{3}$, and $L_{4}$ calculated using $\psi_{\mathrm{aw}}-k_{\mathrm{ra}}$ $-S_{\mathrm{w}}$ curve No. 2 are approximately 1.0 (Table 3 ); in fact, they are closer to 1.0 than those obtained with the $\psi_{\text {aw }}-$ $k_{\text {ra }}-S_{\mathrm{w}}$ curve No. 1 (Table 2). Each air permeability coefficient calculated from gradient $E$ between $\psi_{\text {atm }}^{2}-\psi_{\text {a }}^{2}$ and $L_{1}, L_{2}, L_{3}$, or $L_{4}$ is approximately equal to that used in the numerical simulation (Table 3). If $\psi_{\mathrm{aw}}-k_{\mathrm{ra}}-S_{\mathrm{w}}$ curve No. 1 is used for the numerical simulation, a large variation in the degree of water saturation might cause a significant difference between the air permeability coefficient calculated from the air pressure head and that used in the simulation. However, whichever $\psi_{\mathrm{aw}}-k_{\mathrm{ra}}-S_{\mathrm{w}}$ curve, No. 1 or No. 2, is used, the coefficient of air permeability can be calculated from the gradient $E$ between $\psi_{\mathrm{atm}}^{2}-\psi_{\mathrm{a}}^{2}$ and $L_{1}, L_{2}, L_{3}$, or $L_{4}$, and the estimated

Table 2. Comparison between the air permeability coefficient used in the simulation and the air permeability coefficients calculated from the distribution of the air pressure head obtained by the finite-element method for air-water two-phase flow in soil using $\psi_{\text {aw }}-k_{\text {ra }}-S_{\mathrm{w}}$ curve No. 1

\begin{tabular}{|c|c|c|c|c|c|c|c|c|c|c|}
\hline \multirow{3}{*}{$\begin{array}{l}\text { Coefficient } \\
\text { with } \\
\text { distance }\end{array}$} & \multirow{3}{*}{$\begin{array}{l}\text { Volumetric } \\
\text { discharge } \\
\text { of air } \\
\left(\mathrm{m}^{3} / \mathrm{min}\right)\end{array}$} & \multirow{2}{*}{\multicolumn{2}{|c|}{$\begin{array}{l}\text { Location of the } \\
\text { screen }\end{array}$}} & \multirow{3}{*}{$\begin{array}{l}\text { Relative } \\
\text { viscosity } \\
\text { of air }\end{array}$} & \multirow{3}{*}{$\begin{array}{l}\text { Atmosphere } \\
\text { pressure } \\
\text { head }(\mathrm{m})\end{array}$} & \multicolumn{5}{|c|}{$\psi_{\mathrm{aw}}-k_{\mathrm{ra}}-S_{\mathrm{w}}$ curve No. 1} \\
\hline & & & & & & \multicolumn{2}{|c|}{$\begin{array}{l}\text { Regresion expression between } \\
L_{1}, L_{2}, L_{3}, L_{4} \text { and } \psi_{\mathrm{atm}}^{2}-\psi_{\mathrm{a}}^{2} \\
\end{array}$} & \multirow{2}{*}{$\begin{array}{l}\text { Air } \\
\text { permeability } \\
\text { coefficient } \\
(\mathrm{cm} / \mathrm{s})\end{array}$} & \multirow{2}{*}{$\begin{array}{l}\text { Air } \\
\text { permeability } \\
\text { coefficient } \\
\text { used in the } \\
\text { simulation } \\
(\mathrm{cm} / \mathrm{s})\end{array}$} & \multirow{2}{*}{$\begin{array}{l}\text { Difference } \\
(\mathrm{cm} / \mathrm{s})\end{array}$} \\
\hline & & $\begin{array}{l}\text { Upper } \\
(\mathrm{m})\end{array}$ & $\begin{array}{l}\text { Lower } \\
(\mathrm{m})\end{array}$ & & & $\begin{array}{l}\text { Correlation } \\
\text { coefficien }\end{array}$ & $\begin{array}{l}\text { Gradient } \\
\left(\mathrm{m}^{2}\right)\end{array}$ & & & \\
\hline$L_{1}$ & \multirow{4}{*}{0.06} & - & - & \multirow{4}{*}{$1.80 \mathrm{E}-02$} & \multirow{4}{*}{10.34} & 0.9971 & 4.712 & $6.290 \mathrm{E}-04$ & \multirow{4}{*}{$3.81 \mathrm{E}-04$} & $2.480 \mathrm{E}-04$ \\
\hline$L_{2}$ & & & & & & 0.9975 & 9.899 & $5.988 \mathrm{E}-04$ & & $2.178 \mathrm{E}-04$ \\
\hline$L_{3}$ & & 4.75 & 5.25 & & & 0.9975 & 10.674 & $5.553 \mathrm{E}-04$ & & $1.743 \mathrm{E}-04$ \\
\hline$L_{4}$ & & & & & & 0.998 & 8.267 & $7.170 \mathrm{E}-04$ & & $3.360 \mathrm{E}-04$ \\
\hline
\end{tabular}

Table 3. Comparison between the air permeability coefficient used in the simulation and the air permeability coefficients calculated from the distribution of the air pressure head obtained by the finite-element method for air-water two-phase flow in soil using $\psi_{\mathrm{aw}}-k_{\mathrm{ra}}-S_{\mathrm{w}}$ curve No. 2

\begin{tabular}{|c|c|c|c|c|c|c|c|c|c|c|}
\hline \multirow{3}{*}{$\begin{array}{l}\text { Coefficient } \\
\text { with } \\
\text { distance }\end{array}$} & \multirow{3}{*}{$\begin{array}{l}\text { Volumetric } \\
\text { discharge } \\
\text { of air } \\
\left(\mathrm{m}^{3} / \mathrm{min}\right)\end{array}$} & \multirow{2}{*}{\multicolumn{2}{|c|}{$\begin{array}{l}\text { Location of the } \\
\text { screen }\end{array}$}} & \multirow{3}{*}{$\begin{array}{l}\text { Relative } \\
\text { viscosity } \\
\text { of air }\end{array}$} & \multirow{3}{*}{$\begin{array}{c}\text { Atmosphere } \\
\text { pressure } \\
\text { head }(\mathrm{m})\end{array}$} & \multicolumn{5}{|c|}{$\psi_{\mathrm{aw}}-k_{\mathrm{ra}}-S_{\mathrm{w}}$ curve No. 2} \\
\hline & & & & & & \multicolumn{2}{|c|}{$\begin{array}{l}\text { Regresion expression between } \\
L_{1}, L_{2}, L_{3}, L_{4} \text { and } \psi_{\text {atm }}^{2}-\psi_{\mathrm{a}}^{2}\end{array}$} & \multirow{2}{*}{$\begin{array}{c}\text { Air } \\
\text { permeability } \\
\text { coefficient } \\
(\mathrm{cm} / \mathrm{s})\end{array}$} & \multirow{2}{*}{$\begin{array}{c}\text { Air } \\
\text { permeability } \\
\text { coefficient } \\
\text { used in the } \\
\text { simulation } \\
(\mathrm{cm} / \mathrm{s})\end{array}$} & \multirow[b]{2}{*}{$\begin{array}{l}\text { Difference } \\
(\mathrm{cm} / \mathrm{s})\end{array}$} \\
\hline & & $\begin{array}{l}\text { Upper } \\
\text { (m) }\end{array}$ & $\begin{array}{l}\text { Lower } \\
\text { (m) }\end{array}$ & & & $\begin{array}{l}\text { Correlation } \\
\text { coefficien }\end{array}$ & $\begin{array}{l}\text { Gradient } \\
\left(\mathrm{m}^{2}\right)\end{array}$ & & & \\
\hline$L_{1}$ & \multirow[b]{2}{*}{0.06} & - & - & \multirow[b]{2}{*}{$1.80 \mathrm{E}-02$} & \multirow[b]{2}{*}{10.34} & 0.9995 & 2.925 & $1.013 \mathrm{E}-03$ & \multirow[b]{2}{*}{$9.81 \mathrm{E}-04$} & $3.223 \mathrm{E}-05$ \\
\hline $\begin{array}{l}L_{2} \\
L_{3}\end{array}$ & & 4.75 & 5.25 & & & $\begin{array}{l}0.9996 \\
0.9946 \\
0.9994\end{array}$ & $\begin{array}{l}5.867 \\
6.303 \\
5.956\end{array}$ & $\begin{array}{l}1.010 \mathrm{E}-03 \\
9.404 \mathrm{E}-04 \\
9.952 \mathrm{E}-04\end{array}$ & & $\begin{array}{r}2.929 \mathrm{E}-05 \\
-4.059 \mathrm{E}-05 \\
1.420 \mathrm{E}-05\end{array}$ \\
\hline
\end{tabular}


air permeability coefficient should be accurate within one order of magnitude. The coefficient of air permeability calculated from the gradient $E$ indicates the value depending on the degree of water saturation from the extraction well to the monitoring well, but this coefficient of air permeability is not necessarily equal to that in the neighborhood of the monitoring.

\section{PROCEDURE FOR DETERMINING THE RADIUS OF VACUUM INFLUENCE}

The radius of vacuum influence can be defined as the location where $\psi_{\mathrm{atm}}^{2}-\psi_{\mathrm{a}}^{2}$ becomes zero in radial coordinates at the level of the center of the screen in the extraction well. The radius of vacuum influence is useful for determining the region in which hazardous chemical substances are removed from the air phase of the soil.

The regression line between $\psi_{\mathrm{atm}}^{2}-\psi_{\mathrm{a}}^{2}$ and $L_{3}$ or $L_{4}$ intersects the origin of the coordinate systems, where $L_{3}$ or $L_{4}=0$ and $\psi_{\mathrm{atm}}^{2}-\psi_{\mathrm{a}}^{2}=0$ (Fig. 11). In contrast, the regression line between $\psi_{\mathrm{atm}}^{2}-\psi_{\mathrm{a}}^{2}$ and $L_{1}$ or $L_{2}$ crosses the $L_{1}$ or $L_{2}$ axis, where $\psi_{\mathrm{atm}}^{2}-\psi_{\mathrm{a}}^{2}=0$, with positive values. This can be clearly seen in Fig. 12, where the values of both $L_{1}$ and $L_{2}$ become small far from the extraction well. The point of intersection with the $L_{1}$ or $L_{2}$ axis can be used to determine the radius of vacuum influence when the air permeability test is conducted. The regression expression does not cross the origin of the coordinate system in Fig. 12 because the boundary conditions for Eqs. (3) and (4) are different from those of the numerical model in which both the groundwater table and the ground surface are taken into consideration. On the other hand, the boundary conditions assigned to Eqs. (5) and (6) are more similar to those of the numerical simulation.

$L_{10}$ and $L_{20}$ are the points where the regression line between $\psi_{\text {atm }}^{2}-\psi_{\mathrm{a}}^{2}$ and $L_{1}$ or $L_{2}$ crosses the $L_{1}$ or $L_{2}$ axis, respectively (Fig. 12). For $L_{1}$, the radius $r_{0}$ of vacuum influence can be obtained by using Eq. (14a), which is derived from Eq. (8a) for $z=z^{\prime}$ :

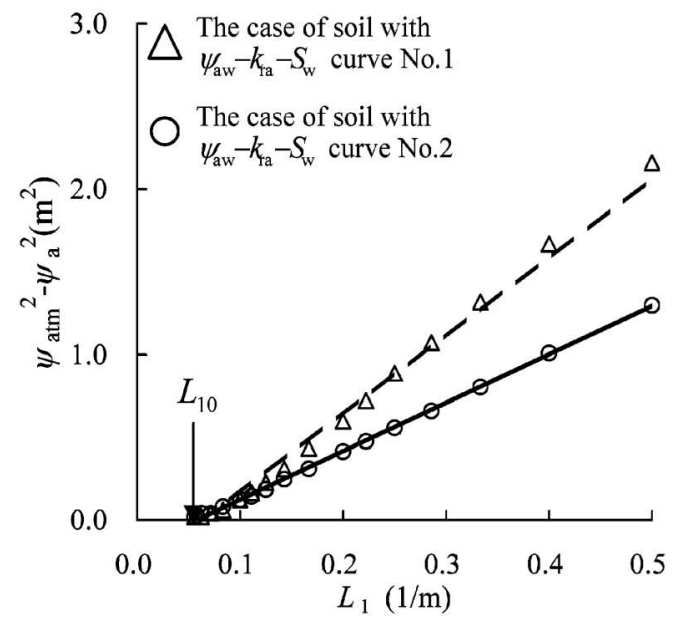

$$
r_{0}=\frac{1}{L_{10}}
$$

Similarly, for $L_{2}$, the radius $r_{0}$ of vacuum influence is obtained by Eq. (14b), which is derived from Eq. (8b) for $z=(a+b) / 2$.

$$
r_{0}=\left\{\left(\frac{a-b}{2} \frac{\left(1+e^{L_{20}}\right)}{1-e^{L_{20}}}\right)^{2}-\left(\frac{a-b}{2}\right)^{2}\right\}^{1 / 2}
$$

\section{ESTIMATION OF THE APPLICABILITY OF EQS. (2) TO (6) TO AIR PERMEABILITY TESTS}

As shown above, it was confirmed on the basis of the results of numerical simulations using the finite-element method that the gradient $E$ between $\psi_{\text {atm }}^{2}-\psi_{\text {a }}^{2}$ and $L_{1}, L_{2}$, $L_{3}$, or $L_{4}$ can be obtained and the air permeability coefficient can be calculated with an accuracy within one order of magnitude, in comparison with the air permeability coefficient used in the numerical simulation, by the proposed procedures using Eqs. (2) to (6).

Moreover, formulas used to estimate the radius of vacuum influence have been also presented in this study. However, it is necessary to confirm the applicability of these procedures by performing air permeability tests at actual field sites. Therefore, this study evaluated the applicability of these proposed procedures using the results of air permeability tests at five sites. The air permeability test data presented in this study were provided by the Taisei Corporation and Kajima Corporation and have not been previously published, except those for site A, which have been published by Yasumoto and Kawabata (2000).

\section{Soil Conditions at Each Site}

At site A, Kuroboku soil was distributed from 0 to 2.2 $\mathrm{m}$ depth below the ground surface, and loam from 2.2 to $5.5 \mathrm{~m}$ depth. Silty sand was found at depths below $5.5 \mathrm{~m}$. The groundwater table at this site was $8.2 \mathrm{~m}$ below the

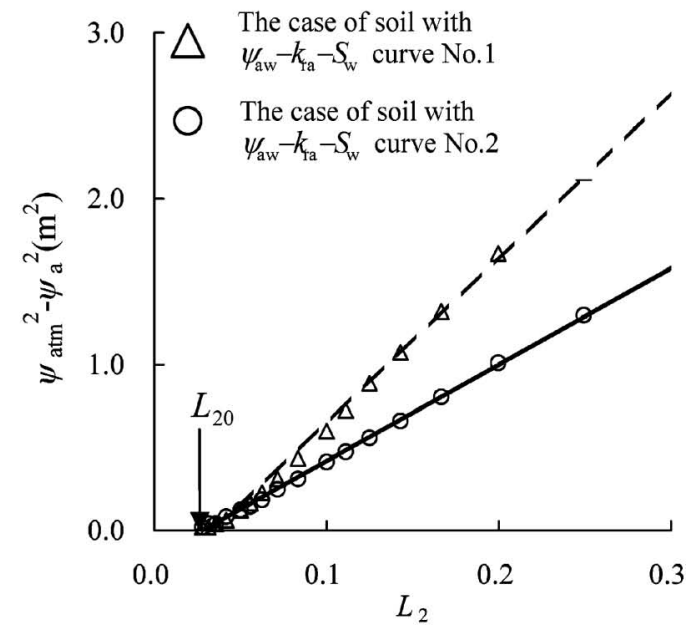

Fig. 12. The relationships between $\psi_{\mathrm{atm}}^{2}-\psi_{\mathrm{a}}^{2}$ and $L_{1}$ (left) and $L_{2}$ (right) when $L_{1}$ and $L_{2}$ are less than 0.5 and 0.3 , respectively. $L_{10}$ and $L_{20}$ are the points where the regression lines intersect the $L_{1}$ and $L_{2}$ axes, respectively 


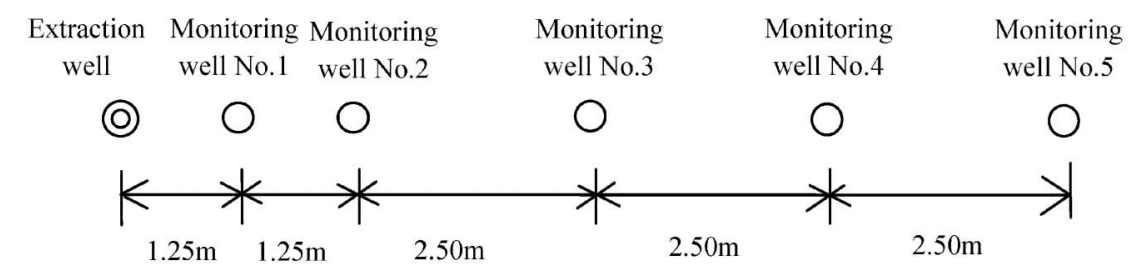

(a) The disposition of an extraction well and monitoring wells.
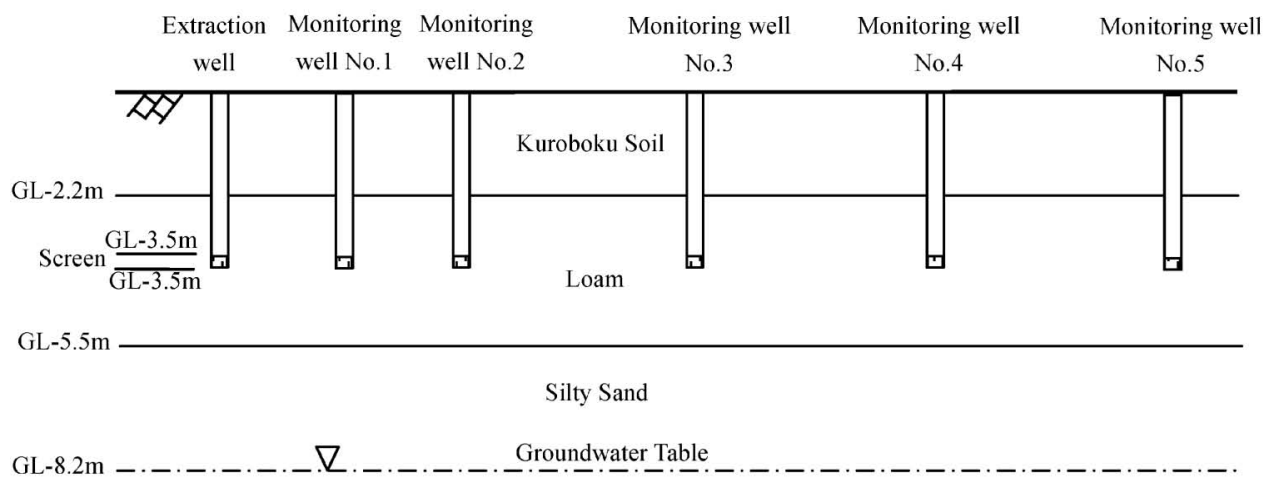

(b) The geological profile.

Fig. 13. The disposition of wells and the geological profile in site A

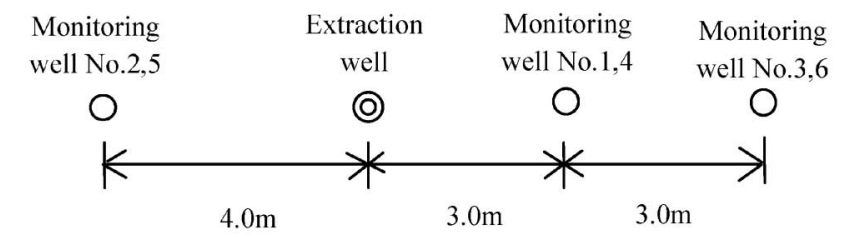

(a) The disposition of an extraction well and monitoring wells.

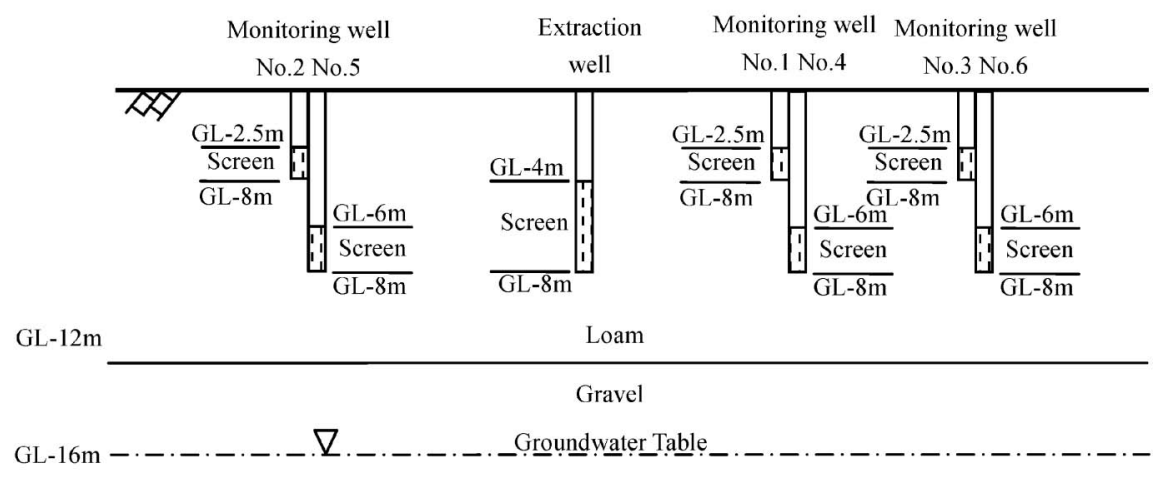

(b) The geological profile.

Fig. 14. The disposition of wells and the geological profile in site B

ground surface, and the screen of the extraction well was installed at depths from 3.5 to $3.75 \mathrm{~m}$, in the loam layer (Fig. 13). At site B, loam was distributed from 0 to 12.0 $\mathrm{m}$ depth, and gravel from $12.0 \mathrm{~m}$ below the ground surface. The groundwater at site B was $16.0 \mathrm{~m}$ below the ground surface, and the screen of the extraction well was installed between 4.0 and $8.0 \mathrm{~m}$ depth (Fig. 14).

At site $\mathrm{C}$, loam was found from 0 to $2.5 \mathrm{~m}$ depth, and clay at depths below $2.5 \mathrm{~m}$. The groundwater table was at $3.65 \mathrm{~m}$ below the ground surface at site $\mathrm{C}$, and the screens of the extraction well and the monitoring wells were in- stalled at depths between 1.2 and $2.7 \mathrm{~m}$ (Fig. 15). At site $\mathrm{D}$, loam, gravel, and clay were distributed from 0 to 4.5 $\mathrm{m}$, from 4.5 to $6.0 \mathrm{~m}$, and below $6.0 \mathrm{~m}$ depth, respectively. The groundwater at site $\mathrm{D}$ was $6.5 \mathrm{~m}$ below the ground surface, which was below the top of the clay. The screen of the extraction well was installed between 2.0 and $3.5 \mathrm{~m}$ in loam. Site E was similar to site D except the screen of the extraction well was installed at 4.5 to $5.5 \mathrm{~m}$ below the ground surface in gravel (Fig. 16).

The air permeability tests at sites A, B, C, and D were thus conducted in the loam, which was composed of silty 


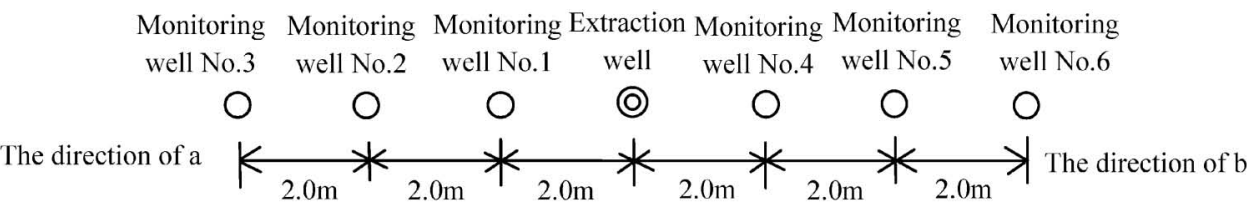

(a) The disposition of an extraction well and monitoring wells.

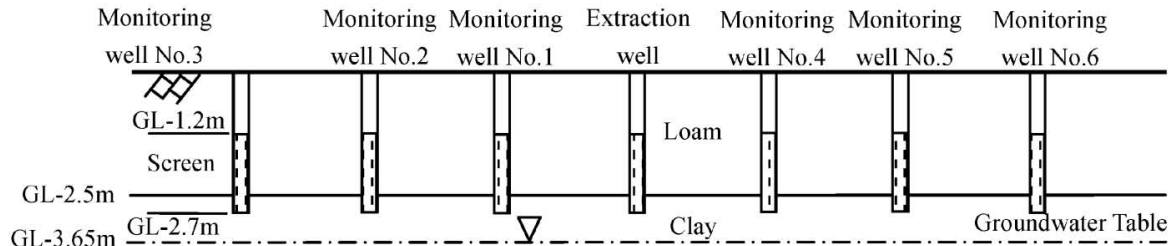

(b) The geological profile.

Fig. 15. The disposition of wells and the geological profile in site $\mathbf{C}$

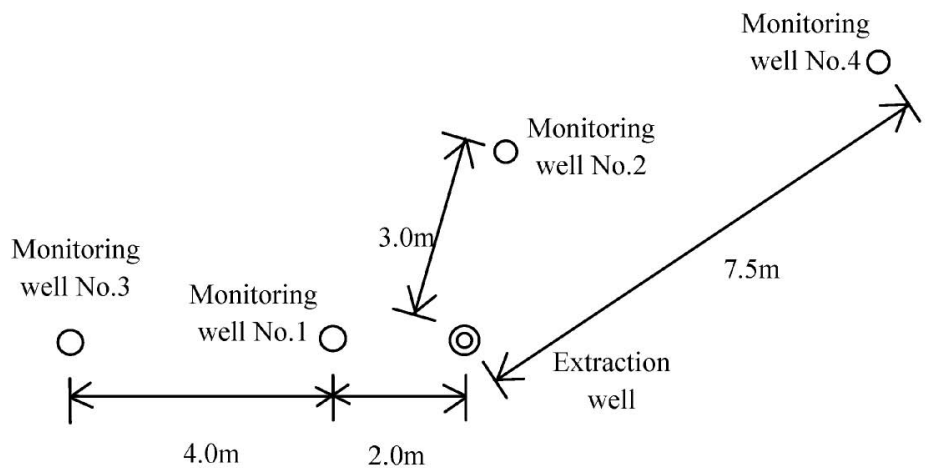

(a) The disposition of an extraction well and monitoring wells.

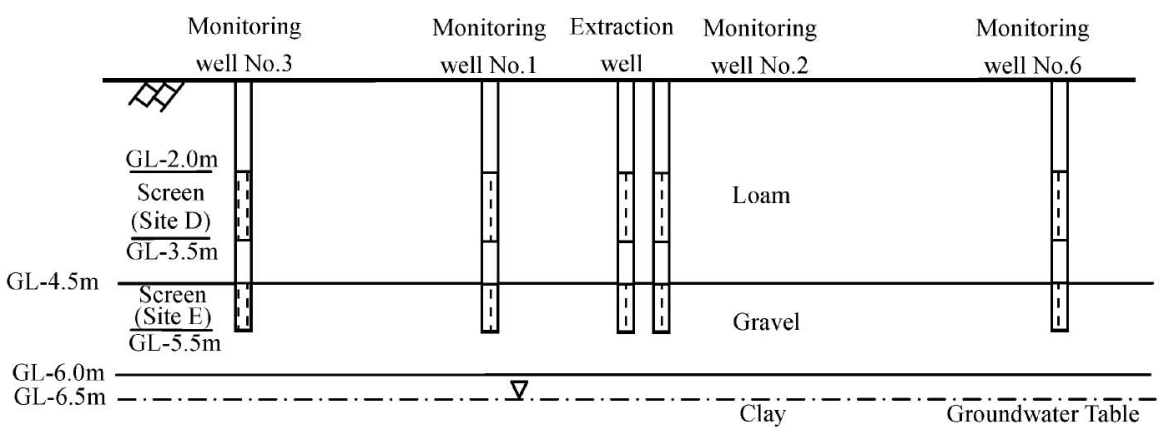

(b) The geological profile.

Fig. 16. The disposition of wells and the geological profile in site $\mathbf{D}$ and $\mathbf{E}$

volcanic ash. On the other hand, at site $\mathrm{E}$ the test was conducted in gravel. Degree of water saturation in the loam, which had high water retentiveness, was more than 0.86 (Yasumoto and Kawabata, 2000). The groundwater table at site $\mathrm{C}$ was a short distance below the screen of the extraction well. Therefore, the screen of the extraction well was closest to the groundwater table at the present sites. The conditions at site $\mathrm{C}$ were similar to those assumed in Eq. (6); because it is generally most difficult to obtain the gradient $E$ in such a situation, it is necessary to show that the gradient $E$ can be obtained from air permeability tests despite the high degree of water satura- tion of the soil. If the gradient $E$ can be obtained in this situation, then it is possible to derive the air permeability coefficient from the air permeability test data. The purpose of the air permeability test at site $\mathrm{E}$ was to evaluate gradient $E$ in a layer with higher permeability than loam.

\section{Evaluation of Gradient $E$ and the Air Permeability Coefficient at Each Site}

Table 4 lists the distances of the monitoring wells from the extraction well, the depth of the screen in the wells, the groundwater table depth, the discharge rate of air, and $\psi_{\mathrm{a}}$ and $\psi_{\mathrm{atm}}$ at sites A, B, C, D, and E. Figures 17, 18, 
Table 4. Well systems used for the air permeability tests, including the groundwater level, the air discharge rate, and the measured air pressure head at sites $\mathrm{A}, \mathrm{B}, \mathrm{C}, \mathrm{D}$, and $\mathrm{E}$

\begin{tabular}{|c|c|c|c|c|c|c|c|c|c|}
\hline \multirow{2}{*}{ Site } & \multirow{2}{*}{\multicolumn{2}{|c|}{ Well }} & \multirow{2}{*}{$\begin{array}{l}\text { Distance } \\
\text { from the } \\
\text { extraction } \\
\text { well }(\mathrm{m})\end{array}$} & \multicolumn{2}{|c|}{ Screen } & \multirow{2}{*}{$\begin{array}{c}\text { Groundwater } \\
\text { level } \\
\text { (GL-m) }\end{array}$} & \multirow{2}{*}{$\begin{array}{l}\text { Discharge } \\
\text { rate of air } \\
\left(\mathrm{m}^{3} / \mathrm{min}\right)\end{array}$} & \multirow{2}{*}{$\begin{array}{c}\text { Genarated air } \\
\text { pressure head } \\
\psi_{\mathrm{a}}(\mathrm{m})\end{array}$} & \multirow{2}{*}{$\begin{array}{c}\text { Atmospheric } \\
\text { pressure head } \\
\psi_{\text {atm }}(\mathrm{m})\end{array}$} \\
\hline & & & & $\begin{array}{l}\text { Upper level } \\
\text { (GL-m) }\end{array}$ & $\begin{array}{l}\text { Lower level } \\
\text { (GL-m) }\end{array}$ & & & & \\
\hline \multirow{16}{*}{ A } & \multicolumn{2}{|c|}{ Extraction well } & 0 & 3.5 & 3.75 & \multirow{16}{*}{8.2} & $1.4,2.1,2.8$ & - & \multirow{16}{*}{10.34} \\
\hline & \multirow{3}{*}{\multicolumn{2}{|c|}{ No. 1}} & 1.25 & 3.5 & 3.75 & & 1.4 & 10.3362 & \\
\hline & & & & & & & 2.1 & 10.3240 & \\
\hline & & & & & & & 2.8 & 10.3000 & \\
\hline & \multirow{12}{*}{$\begin{array}{l}\text { Monitoring } \\
\text { well }\end{array}$} & \multirow[t]{3}{*}{ No. 2} & 2.50 & 3.5 & 3.75 & & 1.4 & 10.3380 & \\
\hline & & & & & & & 2.1 & 10.3290 & \\
\hline & & & & & & & 2.8 & 10.3140 & \\
\hline & & No. 3 & 5.00 & 3.5 & 3.75 & & 1.4 & 10.3390 & \\
\hline & & & & & & & 2.1 & 10.3360 & \\
\hline & & & & & & & 2.8 & 10.3280 & \\
\hline & & No. 4 & 7.50 & 3.5 & 3.75 & & 1.4 & 10.3396 & \\
\hline & & & & & & & 2.1 & 10.3380 & \\
\hline & & & & & & & 2.8 & 10.3330 & \\
\hline & & No. 5 & 10.00 & 3.5 & 3.75 & & 1.4 & 10.3398 & \\
\hline & & & & & & & 2.1 & 10.3390 & \\
\hline & & & & & & & 2.8 & 10.3350 & \\
\hline \multirow{7}{*}{ B } & \multicolumn{2}{|c|}{ Extraction well } & 0 & 4 & 8 & \multirow{7}{*}{16.0} & 0.14 & 8.3400 & \multirow{7}{*}{10.34} \\
\hline & \multirow{6}{*}{$\begin{array}{l}\text { Monitoring } \\
\text { well }\end{array}$} & No. 1 & 3 & 2.5 & 4 & & - & 10.3386 & \\
\hline & & No. 2 & 4 & 2.5 & 4 & & - & 10.3393 & \\
\hline & & No. 3 & 6 & 2.5 & 4 & & - & 10.3399 & \\
\hline & & No. 4 & 3 & 6 & 8 & & - & 10.3378 & \\
\hline & & No. 5 & 4 & 6 & 8 & & - & 10.3390 & \\
\hline & & No. 6 & 6 & 6 & 8 & & - & 10.3398 & \\
\hline \multirow{7}{*}{$\mathrm{C}$} & Extractior & well & 0 & 1.2 & 2.7 & & 1.15 & 10.2100 & \\
\hline & & No. 1 & 2 & 1.2 & 2.7 & & - & 10.2550 & \\
\hline & & No. 2 & 4 & 1.2 & 2.7 & & - & 10.3070 & \\
\hline & & No. 3 & 6 & 1.2 & 2.7 & 2.3 & - & 10.3200 & 10.34 \\
\hline & Monitoring & No. 4 & 2 & 1.2 & 2.7 & & - & 10.3080 & \\
\hline & & No. 5 & 4 & 1.2 & 2.7 & & - & 10.3330 & \\
\hline & & No. 6 & 6 & 1.2 & 2.7 & & - & 10.3350 & \\
\hline & Extractior & well & 0 & 2 & 3.5 & & 2.5 & 10.2400 & \\
\hline & & & & & & & 3.167 & 10.1600 & \\
\hline & & No. 1 & 2 & 2.0 & 3.5 & & 2.5 & 10.3290 & \\
\hline & & & & & & & 3.167 & 10.3250 & \\
\hline & & No. 2 & 3 & 2.0 & 3.5 & & 2.5 & 10.3320 & 10 \\
\hline D & Monitoring & & & & & 6.5 & 3.167 & 10.3290 & 10.34 \\
\hline & well & No. 3 & 6 & 2.0 & 3.5 & & 2.5 & 10.3370 & \\
\hline & & & & & & & 3.167 & 10.3370 & \\
\hline & & No. 4 & 7.5 & 2.0 & 3.5 & & 2.5 & 10.3390 & \\
\hline & & & & & & & 3.167 & 10.3385 & \\
\hline & Extractior & well & 0 & 4.5 & 5.5 & & 3.5 & 10.2800 & \\
\hline & & No. 1 & 2 & 4.5 & 5.5 & & - & 10.3345 & \\
\hline E & Monitoring & No. 2 & 3 & 4.5 & 5.5 & 6.5 & - & 10.3335 & 10.34 \\
\hline & well & No. 3 & 6 & 4.5 & 5.5 & & - & 10.3365 & \\
\hline & & No. 4 & 7.5 & 4.5 & 5.5 & & - & 10.3370 & \\
\hline
\end{tabular}

19, 20, and 21 show the relationships between $\psi_{\mathrm{atm}}^{2}-\psi_{\mathrm{a}}^{2}$ and $L_{1}, L_{2}, L_{3}$, and $L_{4}$ at sites A-E, respectively, where the screen in the extraction well is in loam (sites A-D) or gravel (site E).

Monitoring wells at site A were installed 1.25, 2.50, $5.0,7.5$, and $10.0 \mathrm{~m}$ away from the extraction well, which had a screen from GL-3.5 m to GL-3.75 m (Table 4). $\psi_{\text {atm }}^{2}$ $-\psi_{\text {a }}^{2}$ was proportional to $L_{1}, L_{2}, L_{3}$, and $L_{4}$, except for the highest values of $L_{1}, L_{2}, L_{3}$, and $L_{4}$ for all discharge rates, which were $1.4,2.1$, or $2.8 \mathrm{~m}^{3} / \mathrm{min}$ at site A (Fig. 17). The maximum value of $L_{i}$ was in the neighborhood of the extraction well. This tendency was similar to the relationships between $\psi_{\text {atm }}^{2}-\psi_{\text {a }}^{2}$ and $L_{1}, L_{2}, L_{3}$, and $L_{4}$ obtained by the numerical simulations. $\psi_{\mathrm{atm}}^{2}-\psi_{\mathrm{a}}^{2}$ was proportional to $L_{1}, L_{2}, L_{3}$, and $L_{4}$ within the entire range of variation of $L_{1}, L_{2}, L_{3}$, and $L_{4}$ at site B (Fig. 18). All monitoring wells at site $B$ had two screens, from 2.5 to $4.0 \mathrm{~m}$ and from 6.0 to $8.0 \mathrm{~m}$ below the ground surface, and they were at 3,4 , and $6 \mathrm{~m}$ from the extraction well, which had a screen from 4 to $8 \mathrm{~m}$. The gradients $E$ between $\psi_{\mathrm{atm}}^{2}-\psi_{\mathrm{a}}^{2}$ and $L_{1}, L_{2}, L_{3}$, and $L_{4}$ from 2.5 to $4.0 \mathrm{~m}$ below the ground surface were similar to those from 6.0 

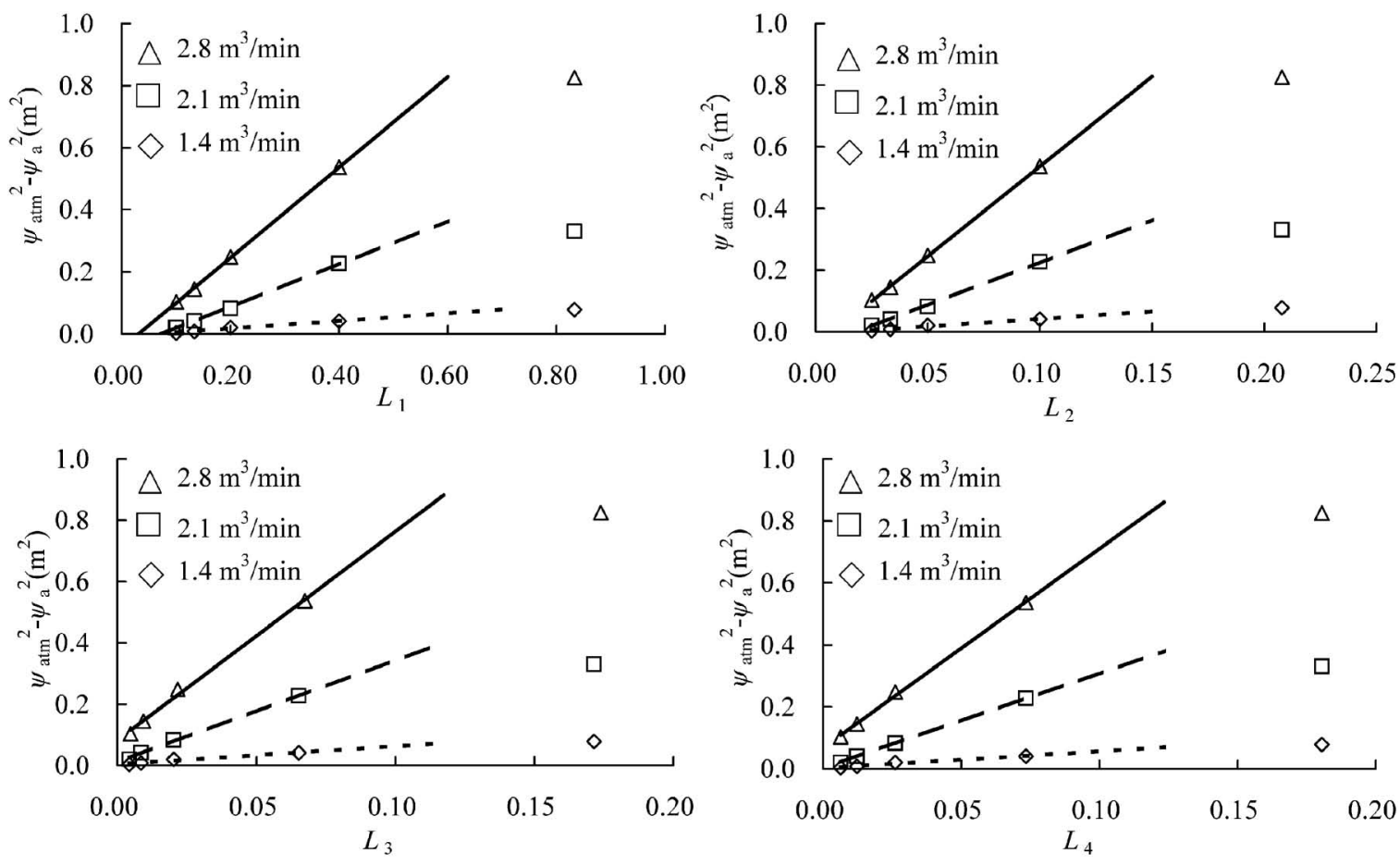

Fig. 17. Evaluation of the proportional relationships between $\psi_{\mathrm{atm}}^{2}-\psi_{\mathrm{a}}^{2}$ and $L_{1}, L_{2}, L_{3}$, and $L_{4}$, at site $\mathrm{A}$ for different discharge rates
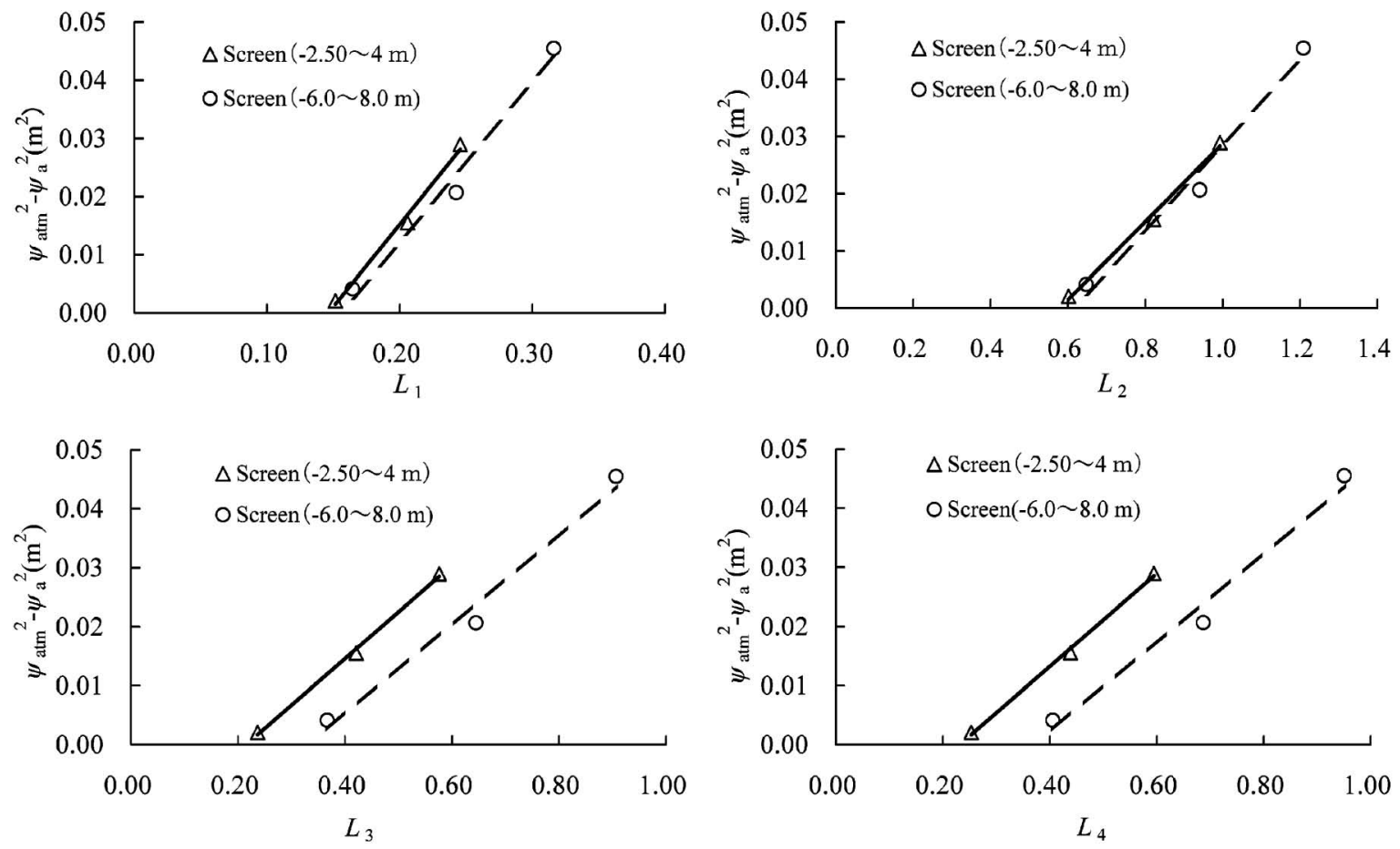

Fig. 18. Evaluation of the proportional relationships between $\psi_{\mathrm{atm}}^{2}-\psi_{\mathrm{a}}^{2}$ and $L_{1}, L_{2}, L_{3}$, and $L_{4}$ at site $\mathrm{B}$ for different screen depths

to $8.0 \mathrm{~m}$ (Fig. 18). The system for the air permeability test at site $\mathrm{C}$ consisted of an extraction well with a screen placed from GL-1.2 $\mathrm{m}$ to GL-2.7 $\mathrm{m}$ and six monitoring wells, which were installed at 2,4 , or $6 \mathrm{~m}$ from the extraction well and had a screen from GL-1.2 $\mathrm{m}$ to GL-2.7 $\mathrm{m}$. Monitoring wells No. 1 to No. 3 were installed opposite the other three monitoring wells (No. 4 to No. 6). The monitoring wells at site D were installed 2, 3, 6, and $7.5 \mathrm{~m}$ from the extraction well. The monitoring wells and the extraction well were screened from 2.0 to $3.5 \mathrm{~m}$ depth. Figures 19 and 20 show the relationship between $\psi_{\text {atm }}^{2}-\psi_{\mathrm{a}}^{2}$ and $L_{1}, L_{2}, L_{3}$, and $L_{4}$ at sites $\mathrm{C}$ and $\mathrm{D}$, respectively; $\psi_{\mathrm{atm}}^{2}$ $-\psi_{\mathrm{a}}^{2}$ is proportional to $L_{1}, L_{2}, L_{3}$, and $L_{4}$ over the entire range of $L_{1}, L_{2}, L_{3}$, and $L_{4}$. However, gradient $E$ between 

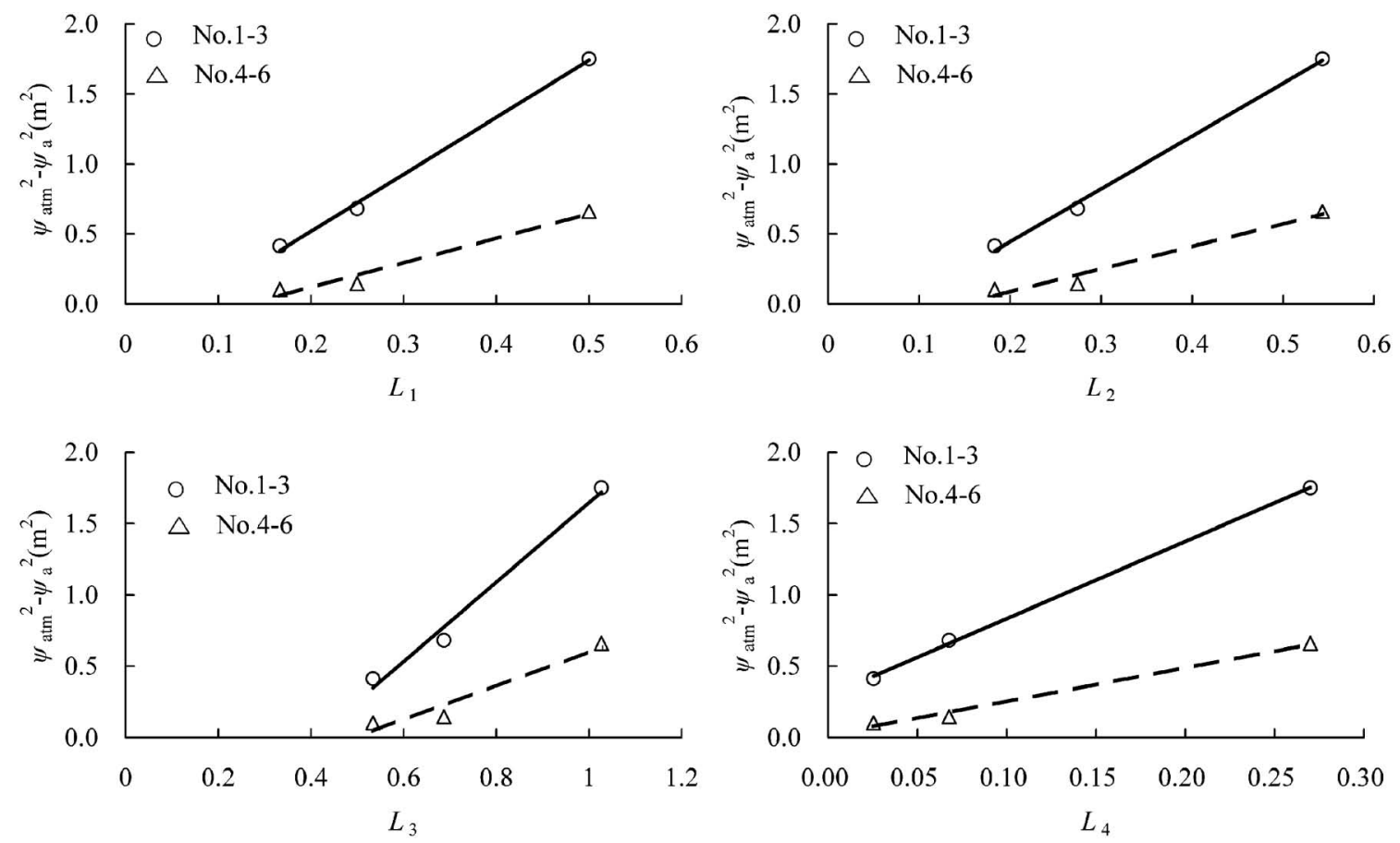

Fig. 19. Evaluation of the proportional relationships between $\psi_{\mathrm{atm}}^{2}-\psi_{\mathrm{a}}^{2}$ and $L_{1}, L_{2}, L_{3}$, and $L_{4}$ at site $\mathrm{C}$
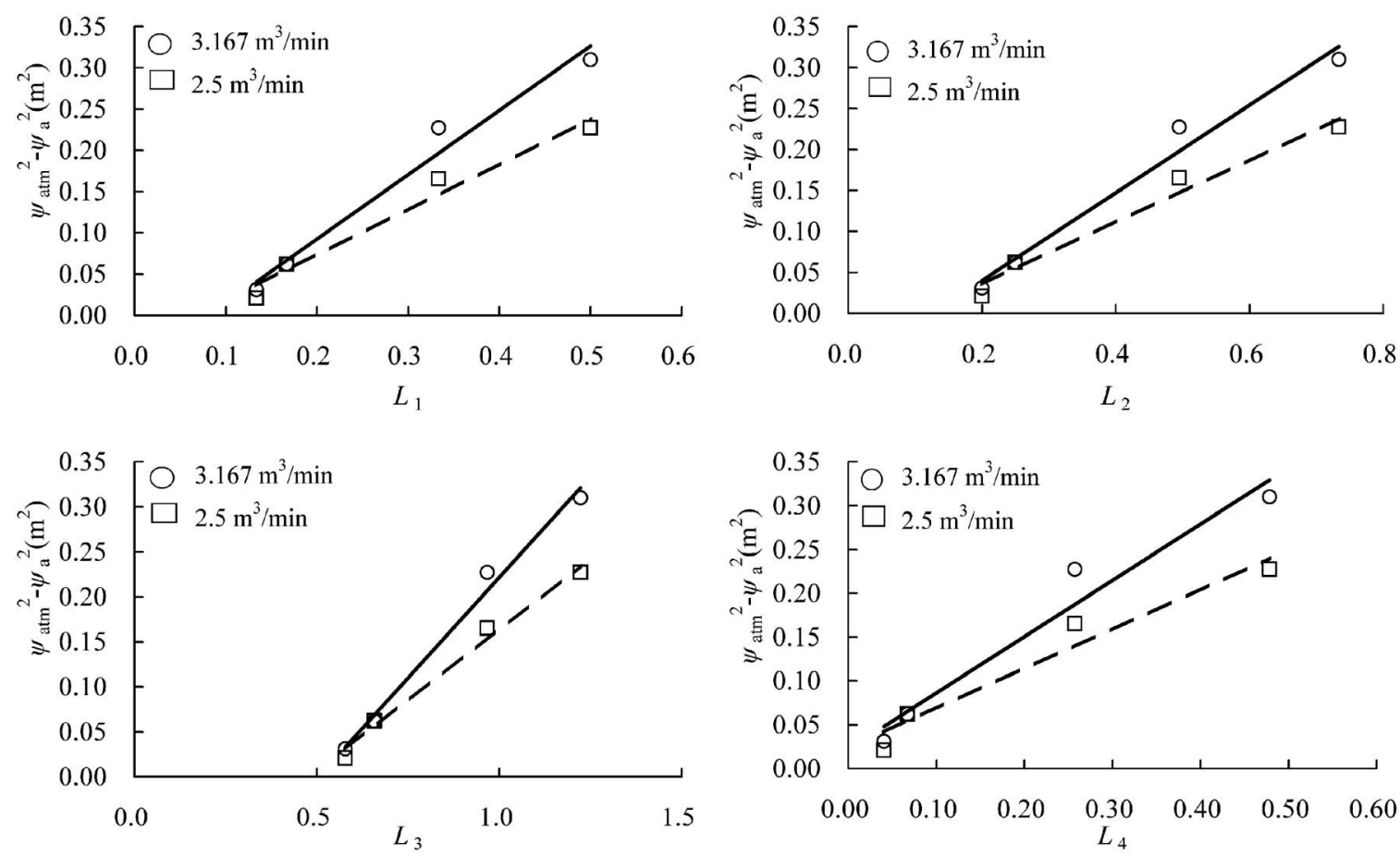

Fig. 20. Evaluation of the proportional relationships between $\psi_{\mathrm{atm}}^{2}-\psi_{\mathrm{a}}^{2}$ and $L_{1}, L_{2}, L_{3}$, and $L_{4}$ at site $\mathrm{D}$ for different discharge rates

$\psi_{\text {atm }}^{2}-\psi_{\mathrm{a}}^{2}$ and $L_{1}, L_{2}, L_{3}$, and $L_{4}$ determined at monitoring wells No. 1 to No. 3 differs from that determined from monitoring wells No. 4 to No. 6 (Fig. 19). Therefore, the soil conditions or groundwater table must differ between wells No. 1 to No. 3 and wells No. 4 to No. 6 at site C. It is obvious that $\psi_{\mathrm{atm}}^{2}-\psi_{\mathrm{a}}^{2}$ at site $\mathrm{D}$ is proportional to $L_{1}$, $L_{2}, L_{3}$, and $L_{4}$ for a discharge rate at the extraction well of 2.5 or $3.167 \mathrm{~m}^{3} / \mathrm{min}$ (Fig. 20). Figure 21 shows the relationships between $\psi_{\mathrm{atm}}^{2}-\psi_{\mathrm{a}}^{2}$ and $L_{1}, L_{2}, L_{3}$, and $L_{4}$ at site $\mathrm{E}$ when the discharge rate at the extraction well was $3.5 \mathrm{~m}^{3} / \mathrm{min}$. As mentioned above, the conditions of the air permeability test at site $\mathrm{E}$ were similar to those at site $D$, except that the screens of the extraction well and the monitoring wells were from GL-4.5 $\mathrm{m}$ to GL-5.5 $\mathrm{m}$ at site E. Although the relationships between $\psi_{\mathrm{atm}}^{2}-\psi_{\mathrm{a}}^{2}$ and $L_{1}$, $L_{2}, L_{3}$, and $L_{4}$ at site $\mathrm{E}$ appear to be proportional (Fig. 

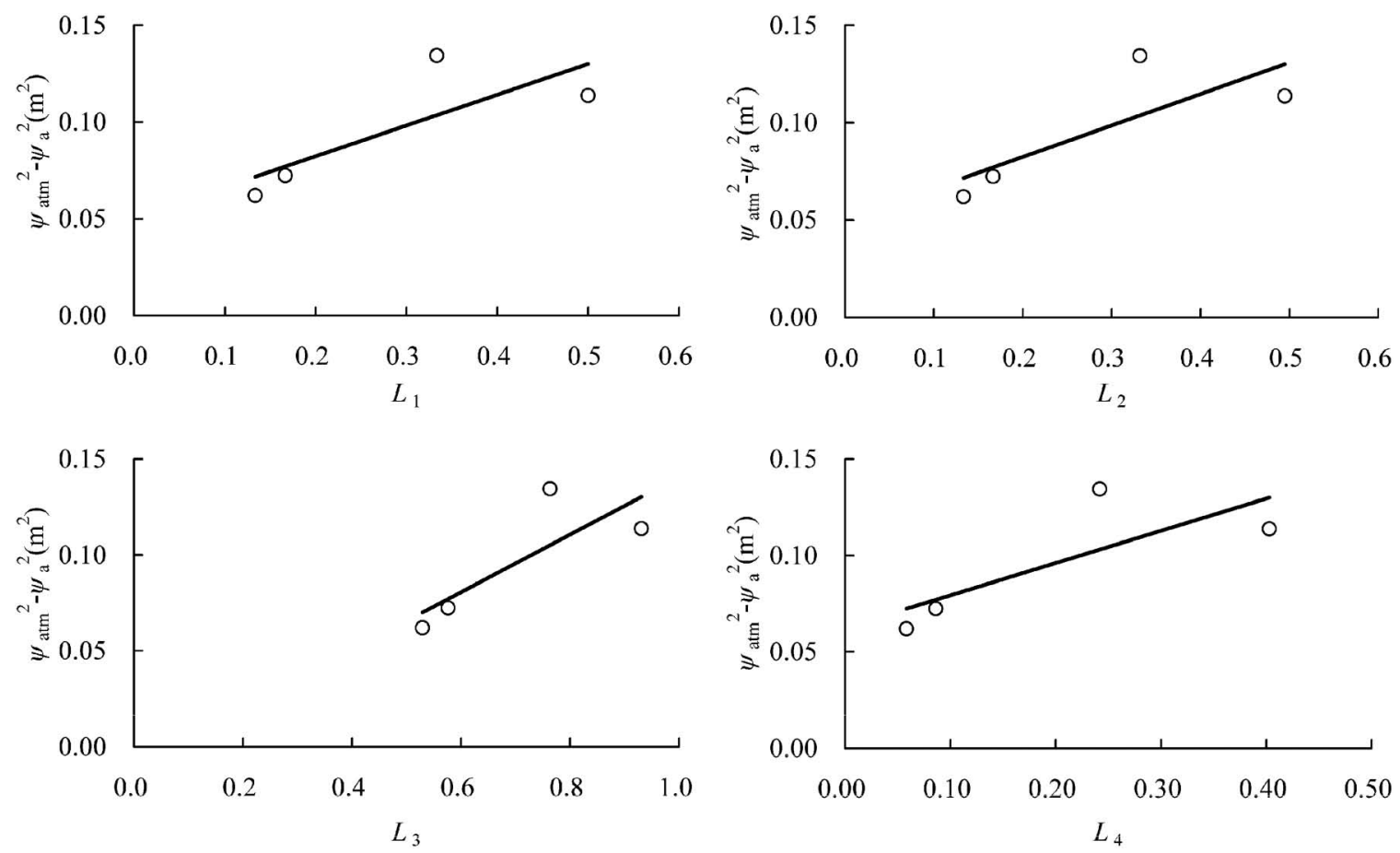

Fig. 21. Evaluation of the proportional relationships between $\psi_{\mathrm{atm}}^{2}-\psi_{\mathrm{a}}^{2}$ and $L_{1}, L_{2}, L_{3}$, and $L_{4}$ at site $\mathrm{E}$

21), the values are more widely scattered than those observed at other sites. The correlation coefficients between $\psi_{\mathrm{atm}}^{2}-\psi_{\mathrm{a}}^{2}$ and $L_{1}, L_{2}, L_{3}$, and $L_{4}$ are more than 0.9 at sites A, B, C, and D; thus, $\psi_{\mathrm{atm}}^{2}-\psi_{\mathrm{a}}^{2}$ is correlated with $L_{1}, L_{2}$, $L_{3}$, and $L_{4}$ (Table 5). On the other hand, the correlation coefficients between $\psi_{\mathrm{atm}}^{2}-\psi_{\mathrm{a}}^{2}$ and $L_{1}, L_{2}, L_{3}$, or $L_{4}$ are only 0.60 to 0.65 at site $E$, presumably because of the fast flow of air in gravel. Therefore, it can be concluded that gradients $E$ between $\psi_{\text {atm }}^{2}-\psi_{\mathrm{a}}^{2}$ and $L_{1}, L_{2}, L_{3}$, and $L_{4}$ can be calculated in a highly permeable layer as well as one with lower permeability, but in the former case, more precise measurement of the air pressure head is required to obtain gradient $E$.

Table 5 also shows the air permeability coefficients obtained from the gradients $E$ at each site. The air permeability coefficient obtained from $L_{1}$ at site A is approximately 16 times those obtained from $L_{2}, L_{3}$, or $L_{4}$. A similar difference between the air permeability coefficient obtained from $L_{1}$ and those obtained from $L_{2}, L_{3}$, or $L_{4}$ was not found at the other sites. Although at site $C$ the air permeability coefficients obtained from $L_{1}, L_{2}, L_{3}$, and $L_{4}$ are scattered, the differences do not exceed one order of magnitude. The air permeability coefficients from monitoring wells No. 1 to No. 3 are smaller than those from wells No. 4 to No. 6 at site C because of the anisotropic soil conditions. Therefore, it can be concluded that the position of the monitoring wells is important, as revealed by the results at site $C$, because the air permeability coefficient differs among monitoring wells where the soil conditions is anisotropic. The simplified procedure suggested here yields realistic estimates of the air permeability coefficient for all tested conditions (Table 5). Therefore, the air permeability coefficient can be obtained by the proposed procedures with $L_{2}, L_{3}$, or $L_{4}$, and the accuracy of the results with these procedures is within one order of magnitude.

Figure 22 shows the relationship between the air discharge rate from the extraction well and the air permeability coefficient at sites $\mathrm{A}$ and $\mathrm{D}$, in loam. Although the air permeability coefficient is independent of the discharge rate if the air flow obeys Darcy's law, the air permeability coefficients obtained at sites A and D decreased as the discharge rates increased (Fig. 22). The numerical solution shown in Fig. 9(a) suggests that the air permeability coefficient decreases with increasing degree of water saturation near the screen in the extraction well when air is extracted from soils with high degree of water saturation. The loams at sites A and D had a high degree of water saturation. The increase in degree of water saturation during the extraction of air occurred close to the screen in the extraction well and decreased the air permeability coefficient as the air discharge rate increases. Therefore, the proposed procedure can be used to obtain the air permeability coefficient from the air permeability test data provided that the discharge rate from the extraction well is adequate and the monitoring well is appropriately located. However, we should avoid employing data from close to the extraction well to obtain the air permeability coefficient. The simpler procedure proposed in this study is useful for obtaining the air permeability coefficient in heterogeneous and anisotropic soil. Air permeability tests conducted in a laboratory can obtain the air permeability coefficients only of local soil and cannot take into account heterogeneity of the soil or anisotropy. When monitoring wells are installed in concentric circles around the extraction well, the proposed 
Table 5. Soils, groundwater levels, $L_{1}, L_{2}, L_{3}$, and $L_{4}$ coefficients for distance, correlation coefficients and the gradients of the regression expressions between $\psi_{\mathrm{atm}}^{2}-\psi_{\mathrm{a}}^{2}$ and $L_{1}, L_{2}, L_{3}$, and $L_{4}$, and the air permeability coefficients obtained at sites $\mathrm{A}, \mathrm{B}, \mathrm{C}, \mathrm{D}$, and $\mathrm{E}$

\begin{tabular}{|c|c|c|c|c|c|c|c|c|c|c|c|}
\hline \multirow{3}{*}{ Site } & \multirow{3}{*}{ Soil } & \multirow{3}{*}{$\begin{array}{l}\text { Water } \\
\text { level }\end{array}$} & \multicolumn{3}{|c|}{ Extraction well } & \multirow{2}{*}{\multicolumn{2}{|c|}{$\frac{\text { Monitoring well }}{\text { Screen }}$}} & \multicolumn{3}{|c|}{ Relationship between pressure and distances } & \multirow{3}{*}{$\begin{array}{l}\text { Air permeability } \\
\text { coefficient }(\mathrm{cm} / \mathrm{s})\end{array}$} \\
\hline & & & \multicolumn{2}{|c|}{ Screen } & \multirow{2}{*}{$\begin{array}{l}\text { Discharge } \\
\text { rate of air } \\
\left(\mathrm{m}^{3} / \mathrm{min}\right)\end{array}$} & & & \multirow{2}{*}{$\begin{array}{l}\text { Coefficient } \\
\text { for distance }\end{array}$} & \multirow{2}{*}{$\begin{array}{l}\text { Correlation } \\
\text { coefficient }\end{array}$} & \multirow{2}{*}{$\begin{array}{l}\text { Gradient E (m } \mathrm{m}^{2} \text { except } \\
\left.\quad \text { for } L_{1}, 1 / \mathrm{m} \text { if } L_{1}\right)\end{array}$} & \\
\hline & & & $\begin{array}{l}\text { Upper } \\
(\mathrm{GL}-\mathrm{m})\end{array}$ & $\begin{array}{l}\text { Lower } \\
(\text { GL-m) }\end{array}$ & & $\begin{array}{l}\text { Upper } \\
\text { (GL-m) }\end{array}$ & $\begin{array}{l}\text { Lower } \\
(\text { GL-m) }\end{array}$ & & & & \\
\hline \multirow{12}{*}{ A } & \multirow{12}{*}{ Loam } & \multirow{12}{*}{ GL-8.2 m } & \multirow{12}{*}{3.5} & \multirow{12}{*}{3.75} & 2.8 & \multirow{12}{*}{3.5} & \multirow{12}{*}{3.75} & $L_{1}$ & 0.9997 & 1.4549 & $9.5062 \mathrm{E}-02$ \\
\hline & & & & & & & & $L_{2}$ & 0.9997 & 5.8229 & $5.9380 \mathrm{E}-03$ \\
\hline & & & & & & & & $L_{3}$ & 0.9957 & 6.8169 & $5.0722 \mathrm{E}-03$ \\
\hline & & & & & & & & $L_{4}$ & 0.9983 & 6.4287 & $5.3784 \mathrm{E}-03$ \\
\hline & & & & & 2.1 & & & $L_{1}$ & 0.9988 & 0.6932 & $1.4964 \mathrm{E}-01$ \\
\hline & & & & & & & & $L_{2}$ & 0.9988 & 2.7742 & $9.3477 \mathrm{E}-03$ \\
\hline & & & & & & & & $L_{3}$ & 0.9983 & 3.3343 & $7.7774 \mathrm{E}-03$ \\
\hline & & & & & & & & $L_{4}$ & 0.9999 & 3.0666 & $8.4564 \mathrm{E}-03$ \\
\hline & & & & & 1.4 & & & $L_{1}$ & 0.9847 & 0.1234 & $5.6040 \mathrm{E}-01$ \\
\hline & & & & & & & & $L_{2}$ & 0.9847 & 0.4940 & $3.4996 \mathrm{E}-02$ \\
\hline & & & & & & & & $L_{3}$ & 0.9642 & 0.5877 & $2.9417 \mathrm{E}-02$ \\
\hline & & & & & & & & $L_{4}$ & 0.9748 & 0.5430 & $3.1838 \mathrm{E}-02$ \\
\hline \multirow{8}{*}{ B } & \multirow{8}{*}{ Loam } & \multirow{8}{*}{ GL-8.2 m } & & & & 2.5 & 4.0 & $L_{1}$ & 0.9919 & 0.2830 & $2.4436 \mathrm{E}-02$ \\
\hline & & & & & & & & $L_{2}$ & 0.9948 & 0.0684 & $4.0440 \mathrm{E}-01$ \\
\hline & & & & & & & & $L_{3}$ & 0.9977 & 0.0789 & $3.5058 \mathrm{E}-01$ \\
\hline & & & 4 & 8 & 0.14 & & & $L_{4}$ & 0.9976 & 0.0785 & $3.5237 \mathrm{E}-01$ \\
\hline & & & 4 & 8 & 0.14 & 6.0 & 8.0 & $L_{1}$ & 0.9827 & 0.2718 & $2.5443 \mathrm{E}-02$ \\
\hline & & & & & & & & $L_{2}$ & 0.9803 & 0.0734 & $3.7685 \mathrm{E}-01$ \\
\hline & & & & & & & & $L_{3}$ & 0.9827 & 0.0763 & $3.6253 \mathrm{E}-01$ \\
\hline & & & & & & & & $L_{4}$ & 0.9821 & 0.0757 & $3.6540 \mathrm{E}-01$ \\
\hline & & & & & & 1.2 & 2.3 & $L_{1}$ & 0.9973 & 4.0732 & $1.3946 \mathrm{E}-02$ \\
\hline & & & & & & *No. 1 to 3 & & $L_{2}$ & 0.9970 & 3.7719 & $2.2590 \mathrm{E}-02$ \\
\hline & & & & & & & & $L_{3}$ & 0.9862 & 2.7857 & $3.0587 \mathrm{E}-02$ \\
\hline$C$ & Loam & GL-2.3 m & 1.2 & 2.7 & 115 & & & $L_{4}$ & 0.9992 & 5.4092 & $1.5752 \mathrm{E}-02$ \\
\hline$c$ & Loantm & UL- $2.3 \mathrm{~m}$ & 1.2 & 2.1 & 1.10 & 1.2 & 2.3 & $L_{1}$ & 0.9694 & 1.7625 & $3.2229 \mathrm{E}-02$ \\
\hline & & & & & & *No. 4 to 6 & & $L_{2}$ & 0.9683 & 1.6315 & $5.2226 \mathrm{E}-02$ \\
\hline & & & & & & & & $L_{3}$ & 0.9426 & 1.1953 & $7.1284 \mathrm{E}-02$ \\
\hline & & & & & & & & $L_{4}$ & 0.9908 & 2.3641 & $3.6042 \mathrm{E}-02$ \\
\hline & & & & & 3.16 & 2.0 & 3.5 & $L_{1}$ & 0.9749 & 0.7789 & $2.0040 \mathrm{E}-01$ \\
\hline & & & & & & & & $L_{2}$ & 0.9773 & 0.5354 & $4.3730 \mathrm{E}-01$ \\
\hline & & & & & & & & $L_{3}$ & 0.9888 & 0.4467 & $5.2414 \mathrm{E}-01$ \\
\hline D & I oam & GI -6 $5 \mathrm{~m}$ & 20 & 35 & & & & $L_{4}$ & 0.9571 & 0.6425 & $3.6441 \mathrm{E}-01$ \\
\hline D & Loam & GL-6.5 m & 2.0 & 3.3 & 2.5 & 2.0 & 3.5 & $L_{1}$ & 0.9711 & 0.5516 & $2.8297 \mathrm{E}-01$ \\
\hline & & & & & & & & $L_{2}$ & 0.9735 & 0.3791 & $6.1760 \mathrm{E}-01$ \\
\hline & & & & & & & & $L_{3}$ & 0.9879 & 0.3168 & $7.3905 \mathrm{E}-01$ \\
\hline & & & & & & & & $L_{4}$ & 0.9507 & 0.4544 & $5.1525 \mathrm{E}-01$ \\
\hline & & & & & & 4.5 & 5.5 & $L_{1}$ & 0.6187 & 0.1591 & $1.0866 \mathrm{E}+00$ \\
\hline $\mathrm{E}$ & Gravel & GL-6.5 m & 4.5 & 5.5 & 3.5 & & & $L_{2}$ & 0.6222 & 0.1617 & $1.0692 \mathrm{E}+00$ \\
\hline 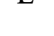 & & & & & & & & $L_{3}$ & 0.6522 & 0.1497 & $1.1549 \mathrm{E}+00$ \\
\hline & & & & & & & & $L_{4}$ & 0.6075 & 0.1673 & $1.0334 \mathrm{E}+00$ \\
\hline
\end{tabular}

*1 Atmospheric pressure head $\psi_{\mathrm{atm}}=10.34 \mathrm{~m}$

*2 Relative viscosity of air $\mu_{\mathrm{a}}=1.8 \times 10^{-2}$

procedures can be used to obtain air permeability coefficients in heterogeneous and anisotropic soils, without complex methods or procedures, from air permeability test data.

\section{Evaluation of the Radius of Vacuum Influence}

Table 6 shows the radius of vacuum influence obtained by using Eqs. (14a) and (14b) at each site. The radius of vacuum influence obtained from $L_{10}$ is similar to that obtained from $L_{20}$ (Table 6). As a result, Eqs. (14a) and (14b) can both be used to calculate the radius of vacuum influence from results of air permeability tests. Equation (14a) has an advantage over Eq. (14b) that the calcula- tion of the radius is simpler. The quantities $L_{10}$ or $L_{20}$ at the intersection between the regression line and the radial axis are negative at site $\mathrm{E}$ (Fig. 21). For this reason the correlation coefficient of the regression is far from 1.0, and $\psi_{\mathrm{atm}}^{2}-\psi_{\mathrm{a}}^{2}$ and $L_{1}$ or $L_{2}$ do not correlate well with each other. Therefore, it is necessary to measure the air pressure head precisely to determine the radius of vacuum influence. The radius of vacuum influence obtained by the proposed procedures is useful for determining the space between wells from which contaminated air in soil is extracted by vacuum pumps. A varying radius of vacuum influence can be obtained when the monitoring wells are installed in concentric circles and the air permeability 
coefficient differs among wells because of anisotropic conditions.

\section{CONCLUSION}

In this study, the air permeability coefficient is evaluated from Eq. (10) and gradients $E$ of the regression lines between $\psi_{\text {atm }}^{2}-\psi_{\text {a }}^{2}$ and $L_{1}, L_{2}, L_{3}$, and $L_{4}$, and the radius of vacuum influence is obtained from point where the regression line intersects the $L_{1}$ or $L_{2}$ axis, where $\psi_{\mathrm{atm}}^{2}-\psi_{\mathrm{a}}^{2}$ is zero. Gradients $E$ and the radius of vacuum influence were obtained from air permeability test data in gravel soil and loam soil with high degree of water saturation using the proposed procedure for air permeability and Eq. (14). The accuracy of the air permeability coefficient obtained by the proposed procedure was within one order of magnitude. Therefore, these procedures are applicable to field conditions.

A simple equation with acceptable precision is more

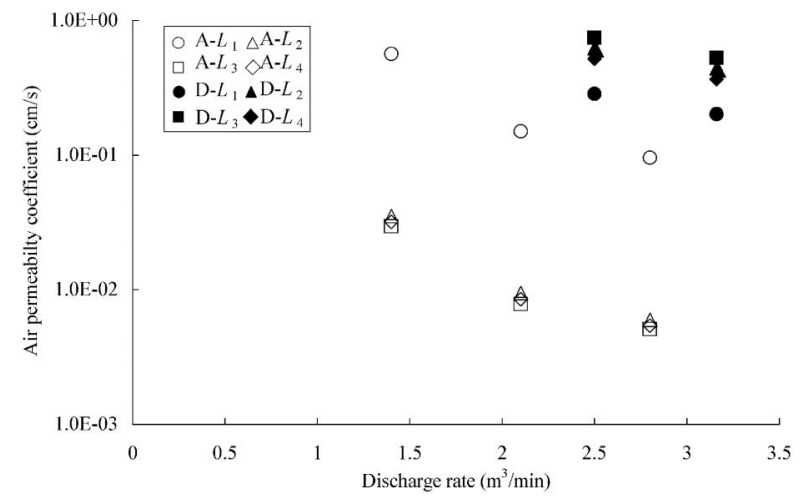

Fig. 22. The relationships between the discharge rate of air and the air permeability coefficient measured at sites $A$ (white symbols) and $D$ (black symbols) convenient than the complex equation to calculate the air permeability coefficient from air permeability test data on site. It was easy to calculate the air permeability coefficient from Eq. (4) or Eq. (5), and both equations yielded sufficiently accurate values for the air permeability coefficient, which was validated by using numerical simulation results. The radius of vacuum influence calculated with Eq. (14a) was equal to that calculated with Eq. (14b), but Eq. (14a) is simpler to use than Eq. (14b). Therefore, the radius of vacuum influence can be most easily obtained with Eq. (14a).

\section{ACKNOWLEDGMENTS}

We acknowledge Taisei Corporation and Kajima Corporation for providing the air permeability test data. We thank Dr. Halim MD. Abdul of Kyushu University for his helpful advice. We are also most grateful for the comments of the reviewers of this article.

\section{REFERENCES}

1) Abriola, L. M. and Pinder, G. F. (1985): A multiphase approach to the modeling of porous media contamination by organic compounds 2. Numerical simulation, Water Resources Research, 21(1), 19-26.

2) Baehr, A. L. and Bruell, C. J. (1990): Application of Stefan-Maxwell equation to determine limitations of Fick's low when modeling organic vapor transport in sand column, Water Resources Research, 26(6), 1155-1163.

3) Baehr, A. L. and Hult, M. F. (1991): Evaluation of unsaturated zone air permeability through pneumatic tests, Water Resources Research, 27(10), 2605-2617.

4) Burdine, N. T. (1953): Relative permeability calculations from pore-size distribution data, Technical report, Petroleum transactions, American Instrument Mining Metal Engineering, 98, 71-77.

5) Celia, M. and Bouloutas, E. T. (1990): A General mass-conservative numerical solution for the unsaturated flow equation, Water Resources Research, 26(7), 1483-1496.

Table 6. Values of intersection $L_{10}$, where the regression line between $\psi_{\mathrm{atm}}^{2}-\psi_{\mathrm{a}}^{2}$ and $L_{1}$ intersects the $L_{1}$ axis, and of intersection $L_{20}$, where the regression line between $\psi_{\mathrm{atm}}^{2}-\psi_{\mathrm{a}}^{2}$ and $L_{2}$ intersects the $L_{2}$ axis, and the radius of vacuum influence values obtained using Eq. (14) and $L_{10}$ or $L_{20}$ at sites $\mathbf{A}, \mathbf{B}, \mathbf{C}, \mathbf{D}$, and $\mathbf{E}$

\begin{tabular}{|c|c|c|c|c|c|c|c|c|c|c|}
\hline \multirow{3}{*}{ Site } & \multirow{3}{*}{ Soil } & \multicolumn{3}{|c|}{ Extraction well } & \multicolumn{2}{|c|}{$\begin{array}{l}\text { Monitoring well } \\
\text { Screen }\end{array}$} & \multicolumn{2}{|r|}{$L_{10}$} & \multicolumn{2}{|r|}{$L_{20}$} \\
\hline & & \multicolumn{2}{|c|}{ Screen } & \multirow{2}{*}{$\begin{array}{l}\text { Discharge of } \\
\text { air }\left(\mathrm{m}^{3} / \mathrm{min}\right)\end{array}$} & \multirow[b]{2}{*}{$\begin{array}{l}\text { Upper } \\
\text { (GL-m) }\end{array}$} & \multirow[b]{2}{*}{$\begin{array}{l}\text { Lower } \\
\text { (GL-m) }\end{array}$} & \multirow[b]{2}{*}{$L_{10}(1 / \mathrm{m})$} & \multirow[b]{2}{*}{$\begin{array}{l}\text { Radius of vacuum } \\
\text { influence }(\mathrm{m})\end{array}$} & \multirow[b]{2}{*}{$L_{20}$} & \multirow[b]{2}{*}{$\begin{array}{l}\text { Radius of vacuum } \\
\text { influence }(\mathrm{m})\end{array}$} \\
\hline & & $\begin{array}{l}\text { Upper } \\
\text { (GL-m) }\end{array}$ & $\begin{array}{l}\text { Lower } \\
\text { (GL-m) }\end{array}$ & & & & & & & \\
\hline \multirow{3}{*}{ A } & \multirow{3}{*}{ Loam } & \multirow{3}{*}{3.5} & \multirow{3}{*}{3.75} & 2.8 & \multirow{3}{*}{3.5} & \multirow{3}{*}{3.75} & 0.03079 & 32.5 & 0.0077 & 32.4 \\
\hline & & & & 2.1 & & & 0.07415 & 13.5 & 0.0185 & 13.5 \\
\hline & & & & 1.4 & & & 0.05754 & 17.4 & 0.0144 & 17.4 \\
\hline \multirow{2}{*}{ B } & \multirow{2}{*}{ Loam } & \multirow{2}{*}{4} & \multirow{2}{*}{8} & \multirow{2}{*}{0.14} & 2.5 & 4.0 & 0.14629 & 6.8 & 0.5775 & 6.8 \\
\hline & & & & & 6.0 & 8.0 & 0.15489 & 6.5 & 0.6117 & 6.4 \\
\hline \multirow[b]{2}{*}{$\mathrm{C}$} & \multirow[b]{2}{*}{ Loam } & \multirow[b]{2}{*}{1.2} & \multirow[b]{2}{*}{2.3} & \multirow[t]{2}{*}{1.15} & 1.2 & 2.3 & 0.07272 & 13.8 & 0.0821 & 13.40 \\
\hline & & & & & $\begin{array}{l}\text { *No. } 1 \text { to } 3 \\
1.2 \\
\text { *No. } 4 \text { to } 6\end{array}$ & 2.3 & 0.13367 & 7.5 & 0.1478 & 7.4 \\
\hline $\mathrm{D}$ & Loam & 2.0 & 3.5 & 2.5 & 2.0 & 3.5 & 0.06780 & 14.7 & 0.1058 & 14.2 \\
\hline $\mathrm{E}$ & Gravel & 4.5 & 5.5 & 3.5 & 4.5 & 5.5 & - & - & - & - \\
\hline
\end{tabular}


6) Davis, E. L. (1994): Effect of temperature and pore size on the hydraulic properties and flow of a hydrocarbon oil in the subsurface, Journal Contaminant Hydrology, 16, 55-86.

7) Gerke, H. H., Hormung, U., Kelanemer, Y., Slodicka, M. and Schumache, S. (1999): Optimal Control of Soil Venting Mathematical Modeling and Applications, Birkhauser Verlag, Base, 6-42.

8) Helmig, R. (1997): Multiphase Flow and Transport Process in the Subsurface, Springer, Berlin, 5-16.

9) Hibi, Y., Fujinawa, K. and Fujiwara, Y. (2001): A comparison of finite element solution for pressure based and mixed type equations of two-phase flow in porous media, International Association for Research Committee on Groundwater Hydraulics 1st Groundwater Seminar between China, Korea and Japan, International Association for Hydraulic Research, Fukuoka, 41-52.

10) Hibi, Y., Jinno, K., Egusa, N., Kawabata, J. and Shimomura, M. (2006a): Prediction of influence radius of vacuum pumping in unsaturated soil and evaluation air permeability by in situ vacuum test, Journal of Environmental System and Engineering, 62(2), 488-501.

11) Hibi, Y., Jinno, K., Egusa, N., Kawabata, J. and Shimomura, M. (2006b): Comparison of the theoretical and numerical solution by the finite element method for steady state air flow in soil toward an extraction well, Journal of Environmental System and Engineering, 62(4), 391-402.

12) Hoeg, S., Scholer, H. F. and Warnatz, J. (2004): Assessment of interfacial mass transfer in water-unsaturated soils during vapor extraction, Journal of Contaminant Hydrology, 74, 163-193.

13) Lenhard, R. J., Oostrom, M., Simmons C. S. and White, M. D. (1995): Investigation of density-dependent gas advection of trichloroethylene: Experiment and a model validation exercise, Journal Contaminant Hydrology, 19, 47-67.

14) McWhorter, D. B. (1990): Unsteady radial flow of gas in the vadose zone, Journal of Contaminant Hydrology, 5, 297-314.

15) Reinecke, S. A. and Sleep, B. E. (2002): Knudsen diffusion, gas permeability, and water saturation in an unconsolidated porous medium, Water Resource Research, 38(12), 16-1-16-15.

16) Shan, C., Falta, R. W. and Javandel, I. (1992): Analytical solution for steady state gas flow to a soil vapor extraction well, Water Resources Research, 28(4), 1105-1120.

17) Sleep, B. E. and Sykes, J. F. (1993): Compositional simulation of groundwater contamination by organic compounds 1 . Model development and verification, Water Resource Research, 29(6), 1697-1708

18) Thorstenson, D. C. and Pollock, D. W. (1989): Gas transport in unsaturated zones: Multicomponent system and the adequacy of Fick's laws, Water Resource Research, 23(3), 477-507.

19) US Army Corps of Engineers (2002): Soil Vapor Extraction and Bioventing Engineer Manual, 1-1-21-22, D-8-E-9.

20) van Genuchten, M. T. (1980): A closed-form equation for predicting the hydraulic conductivity of unsaturated soils, Soil Science Society American Journal, 44, 892-898.

21) Yasumoto, K. and Kawabata, J. (2000): Evaluation of in-situ permeability test for designing soil, Groundwater Updates, 393-398.

\section{APPENDIX: EQUATIONS GOVERNING AIR-WATER TWO-PHASE FLOW}

The law of conservation of mass for steady air flow in soil can be expressed in a cylindrical coordinate system as follows:

$$
\frac{\partial \rho_{\mathrm{a}} V_{\mathrm{ar}}}{\partial r}+\frac{1}{r} \rho_{\mathrm{a}} V_{\mathrm{ar}}+\frac{\partial \rho_{\mathrm{a}} V_{\mathrm{az}}}{\partial z}=0,
$$

where $V_{\text {ar }}$ is the velocity of air in the radial direction and
$V_{\text {az }}$ is the velocity of air in the vertical direction. The velocities obey Darcy's law and can be expressed using the following equations:

$$
\begin{aligned}
& V_{\mathrm{r}}=-\frac{k_{\mathrm{ra}} K_{\mathrm{s}}}{\mu_{\mathrm{ra}}} \frac{\partial \psi_{\mathrm{a}}}{\partial r} \\
& V_{\mathrm{z}}=-\frac{k_{\mathrm{ra}} K_{\mathrm{s}}}{\mu_{\mathrm{ra}}} \frac{\partial\left(\psi_{\mathrm{a}}-\rho_{\mathrm{ra}} z\right)}{\partial z} .
\end{aligned}
$$

The density of air can be expressed by the ideal air equation:

$$
\rho_{\mathrm{a}}=\psi_{\mathrm{a}} M_{\mathrm{a}} \rho_{\mathrm{w}} g / R T
$$

where $R$ is the gas constant $\left[\mathrm{ML}^{2} / \mathrm{mol} \mathrm{kT}^{2}\right], T$ is the temperature [k], and $M_{\mathrm{a}}$ is the molecular weight [M/mol]. When the air pressure head is equal to the atmospheric pressure head $\psi_{\text {atm }}$, the density of air can be expressed as,

$$
\rho_{\text {atm }}=\psi_{\text {atm }} M_{\mathrm{a}} \rho_{\mathrm{w}} g / R T .
$$

Dividing Eq. (17) by Eq. (18) with a constant temperature and rearranging the result gives the following equation:

$$
\rho_{\mathrm{a}}=\psi_{\mathrm{a}} \rho_{\mathrm{atm}} / \psi_{\mathrm{atm}} .
$$

By substituting Eqs. (16) and (19) into Eq. (15), the following equation governing steady air flow in soil is derived:

$$
\begin{gathered}
\frac{\partial}{\partial r}\left(\frac{\psi_{\mathrm{a}} \rho_{\mathrm{atm}}}{\psi_{\mathrm{atm}}} \frac{K_{\mathrm{ra}} k_{\mathrm{s}}}{\mu_{\mathrm{ra}}} \frac{\partial \psi_{\mathrm{a}}}{\partial r}\right)+\frac{1}{r} \frac{\psi_{\mathrm{a}} \rho_{\mathrm{atm}}}{\psi_{\mathrm{atm}}} \frac{K_{\mathrm{ra}} k_{\mathrm{s}}}{\mu_{\mathrm{ra}}} \frac{\partial \psi_{\mathrm{a}}}{\partial r} \\
+\frac{\partial}{\partial z}\left(\frac{\psi_{\mathrm{a}} \rho_{\mathrm{atm}}}{\psi_{\mathrm{atm}}} \frac{K_{\mathrm{ra}} k_{\mathrm{s}}}{\mu_{\mathrm{ra}}} \frac{\partial}{\partial z}\left(\psi_{\mathrm{a}}-\rho_{\mathrm{ra}} z\right)\right)=0 .
\end{gathered}
$$

The velocities of water in soil can be expressed by Darcy's law:

$$
\begin{aligned}
& V_{\mathrm{wr}}=-k_{\mathrm{rw}} K_{\mathrm{s}} \frac{\partial \psi_{\mathrm{w}}}{\partial r} \\
& V_{\mathrm{wz}}=-k_{\mathrm{rw}} K_{\mathrm{s}} \frac{\partial \psi_{\mathrm{w}}-z}{\partial z}
\end{aligned}
$$

The law of conservation of mass for steady water flow in soil can be expressed in the cylindrical coordinate system as follows:

$$
\frac{\partial V_{\mathrm{wr}}}{\partial r}+\frac{1}{r} V_{\mathrm{wz}}+\frac{\partial V_{\mathrm{wz}}}{\partial z}=0
$$

where $V_{\mathrm{wr}}$ is the velocity of water in the radial direction and $V_{\text {wz }}$ is the velocity of water in the vertical direction. The equation governing water flow in soil can then be derived by substituting Eq. (21) into Eq. (22).

$$
\begin{gathered}
\frac{\partial}{\partial r}\left(k_{\mathrm{rw}} K_{\mathrm{s}} \frac{\partial \psi_{\mathrm{w}}}{\partial r}\right)+\frac{k_{\mathrm{rw}} K_{\mathrm{s}}}{r} \frac{\partial \psi_{\mathrm{w}}}{\partial r} \\
+\frac{\partial}{\partial z}\left[k_{\mathrm{rw}} K_{\mathrm{s}} \frac{\partial}{\partial r}\left(\psi_{\mathrm{w}}-z\right)\right]=0
\end{gathered}
$$

